\title{
Un planeta de metrópolis (en crisis). Explosión urbana y del transporte motorizado, gracias al petróleo
}

\section{Ramón Fernández Durán *}

\section{Resumen}

Este trabajo se centra en el análisis del espacio urbano durante el siglo XX, debido a la importancia de la dimensión espacial en el capitalismo global. En homenaje a la obra y la persona de Ramón Fernández Durán recogemos este texto a título póstumo, con el consentimiento del autor y teniendo en cuenta que el texto original ha sido editado bajo licencia Creative Commons. Por ello, adaptado al formato de la revista, se respeta la integridad del texto original.

\section{Abstract: A planet of metropolises (in crisis). The boom of cities and motorised transport thanks to oil}

This paper analyzes the urban space in the 20th century because of the importance of the spatial dimension in global capitalism. This text is posthumously included as a tribute to Ramón Fernández Durán and his works with the author"s consent and considering that the original text was published under a Creative Commons license. For this reason, the original text was adapted to the format of the journal without making any changes.

"Los primeros en abandonar los espacios urbanos no fueron los desheredados, que a fin de cuenta tampoco tenían donde ir, sino los ciudada- nos más poderosos que, hasta entonces, eran los líderes del modo de vida metropolitano (...) Se puede decir que, en cierta forma, los dueños y

\footnotetext{
${ }^{*}$ Miembro de Ecologistas en Acción.
} 
señores abandonaron a su suerte las grandes ciudades. Esto supuso el principio del fin (...)

Cuando las ciudades -abandonadas por los sectores más ricos y cultos-, sufrieron el impacto de las sucesivas ecocrisis del siglo I (después del Error Fatal), se derrumbaron como un castillo de naipes (...) Cuando fallaron los suministros eléctricos, de gas y de agua, el servicio de recogida de basuras, etc., las ciudades se volvieron sencillamente inhabitables. Además, las grandes ciudades costeras, orgullo de la civilización imperial, se inundaron por la subida del nivel de las aguas. A causa de todo ello podemos afirmar que, a fina-

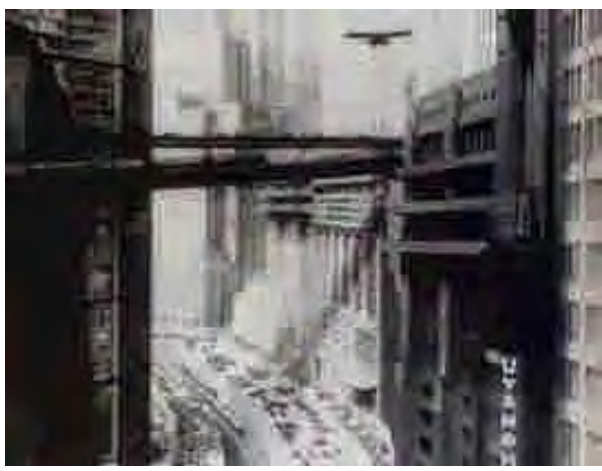

Fotogramas de Metrópolis (Fritz Lang, 1925).

\section{Boom demográfico y estallido metropolitano, potenciado por la energía fósil}

En el siglo $X X$ se ha dado un intenso crecimiento demográfico, absolutamente sin precedentes en la historia de la Humanidad. La población prácticamente se cuadriplicó en este periodo, pasando de 1600 a 6200 millones de habitantes. Esto es, los seres humanos tardaron más de 150.000 años en ser mil millones (en torno a 1830), y poco menos de doscientos años en añadir cinco mil millones más, concentrándose el grueso de ese crecimiento demográfico en el pasado siglo, en especial en su segunda mitad (Christian, 2005) (ver figura 1). Crecimiento que continúa fuerte pero con menor intensidad en el siglo XXI, alcanzando más de 6.600 millones en la actualidad. Este crecimiento no hubiera sido posible sin la explotación de los combustibles fósiles, y muy en concreto sin les de la primera centuria después del Error Fatal, no quedaba prácticamente ninguna "gran ciudad" sobre la faz de la Tierra (...) Abandonados por sus gobernantes, los habitantes de las zonas oscuras volvieron a sus antiguas formas de organización y producción, y consiguieron crear economías de subsistencia independientes del flujo global de la economía. Más tarde se produjo el retorno a estas zonas de millones de emigrantes desengañados de la miseria de los bidonville" Juan Ibarrondo, "Retazos de la red" (novela de política-ficción)

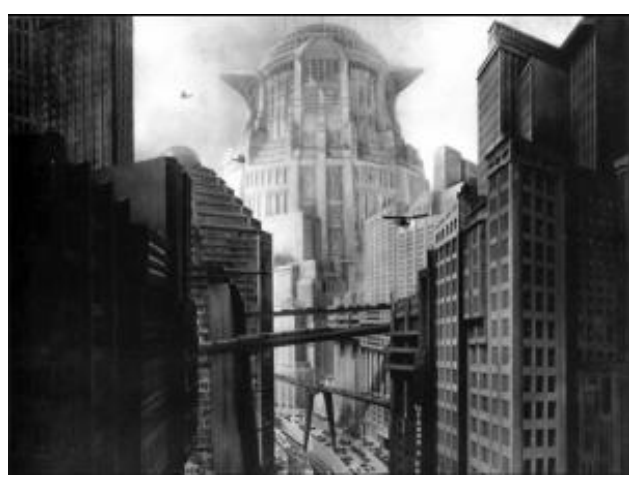

la utilización del petróleo, que es la energía que fundamentalmente ha contribuido a incrementar la capacidad de carga sobre el territorio; garantizando el abastecimiento y el funcionamiento de un mundo en proceso acelerado de urbanización, a través principalmente de la agricultura industrializada y el transporte motorizado. La urbanización del planeta sencillamente se ha disparado en los últimos 100 años, pasando de un $15 \%$ en $1900^{1}$, unos 250 millones de personas, a cerca del $50 \%$ en 2000 , esto es, más de 3000 millones de personas, superando en el presente la mitad de la población mundial. Por primera vez en la historia humana. Es decir, mientras que la población total se multiplicaba "sólo" por cuatro en cien años, la

\footnotetext{
1 Recuérdese que la tasa de urbanización era de un $3 \%$ en 1800, al inicio de la Revolución Industrial, lo que significaba unos 24 millones de personas habitando en ciudades en el mundo, de un total de unos 800 millones entonces, y que sólo existía una metrópoli millonaria: Londres. En 200 años, pues, la población urbana se multiplicó por 120 y el número de ciudades millonarias por 400 .
} 
población urbana se multiplicaba más de doce veces en el mismo periodo. un ritmo tres veces superior. $Y$ este ritmo se aceleró sensiblemente en los últimos cincuenta años del siglo $X X$, al tiempo que el oro negro se convertía en el régimen energético dominante a escala global. No en vano $3 / 4$ partes del petróleo global se consume en las áreas urbanas, especialmente en las metrópolis de los espacios centrales (occidentales) (Beauchard, 1993; Heinberg, 2006; Lee, 2007; Mumford, 1961).

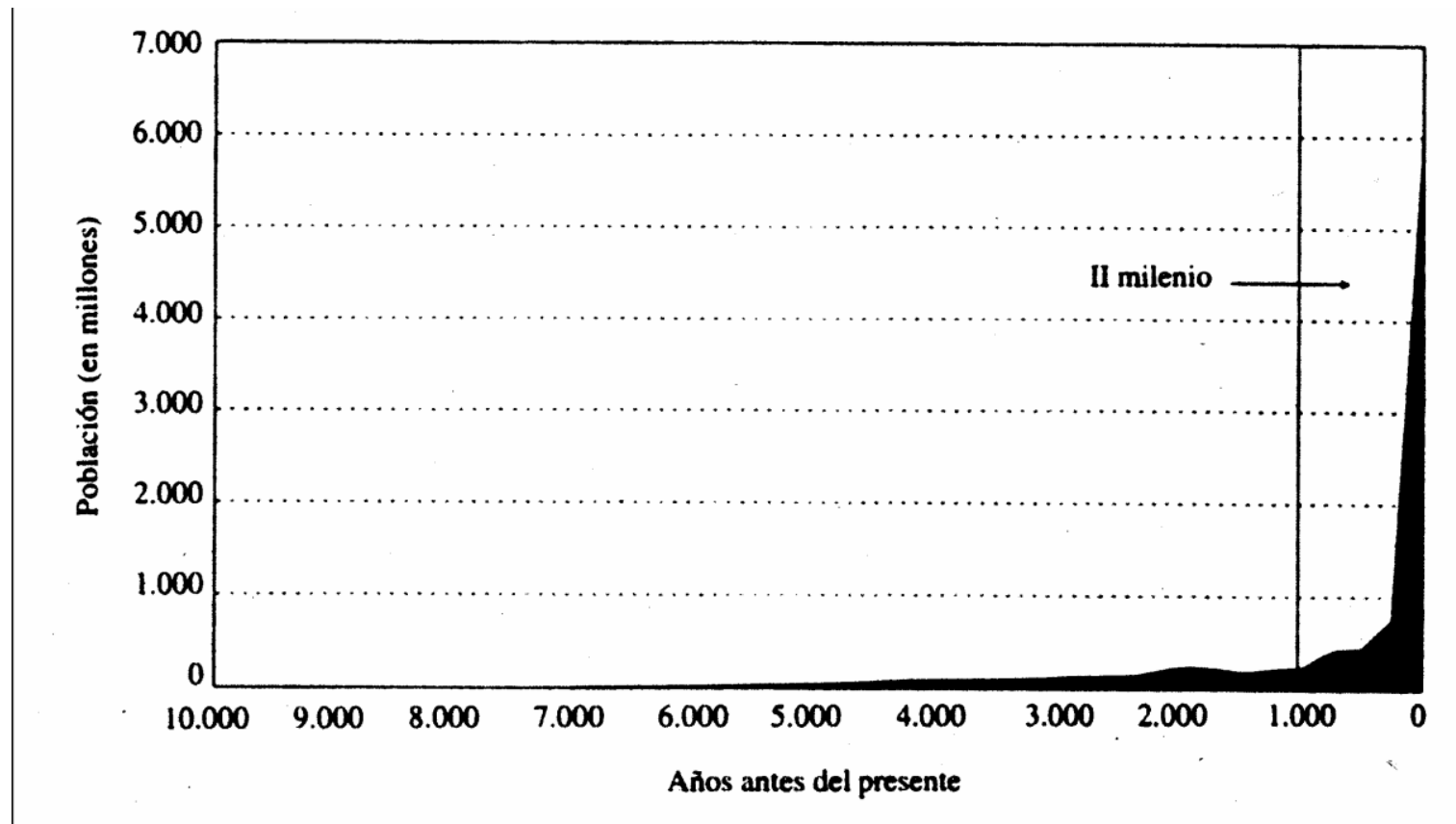

Figura 1. Evolución de la población humana a lo largo de la Historia. Explosión demográfica gracias a la energía fósil. Fuente: Christian, D. "Mapas del Tiempo. Introducción a la Gran Historia”. Barcelona, Crítica, 2005.

${ }^{2}$ Pero si consideramos la población del sistema urbano superior, esto es, las principales "ciudades" del mundo, o mejor dicho las metrópolis, el crecimiento fue aún mucho más intenso. En 1900 había unas diez metrópolis en el planeta que sobrepasaban el millón de habitantes, la práctica totalidad de ella en los países centrales. En 2000 había ya unas 400 metrópolis en el mundo que superaban el millón de habitantes, y de ellas cerca de 70 "Megaciudades", o regiones metropolitanas, que excedían los diez millones de habitantes. $\mathrm{Y}$ en la actualidad hay casi 500 metrópolis

\footnotetext{
2 Recuérdese que la tasa de urbanización era de un 3\% en 1800 , al inicio de la Revolución Industrial, lo que significaba unos 24 millones de personas habitando en ciudades en el mundo, de un total de unos 800 millones entonces, y que sólo existía una metrópoli millonaria: Londres. En 200 años, pues, la población urbana se multiplicó por 120 y el número de ciudades millonarias por 400.
}

millonarias. De éstas, unas son "Ciudades Globales" centrales y otras "Megaciudades Miseria" periféricas, y otras más en los grandes Estados "emergentes" combinarían una mezcla de ambas extremos, como luego veremos. Finalmente, unas cinco de estas grandes conurbaciones se situaban por encima de los 20 millones de habitantes: México DF, Sao Paulo, Seúl, Tokio y Nueva York. Y sólo México DF tiene un volumen de población (unos 24 millones) similar a toda la población urbana que existía en el mundo al inicio de la Revolución Industrial. Así pues, la expansión del crecimiento metropolitano en el pasado siglo ha sido sencillamente impresionante, multiplicándose el número de metrópolis millonarias por cuarenta, casi cuatro veces más rápido que el ritmo de urbanización, y diez veces más rápido que el ritmo de crecimiento demográfico. Sin lugar a dudas, 
podemos afirmar que el siglo $\mathrm{XX}$ ha visto cómo la forma "metrópoli" proliferaba y se extendía sin control por el mundo entero, convirtiéndose en el elemento simbólico determinante de la urbanización mundial. Sin embargo, si consideramos el espacio "tocado" por el proceso urbanometropolitano la cifra de crecimiento aún se dispararía mucho, muchísimo, más, pues las dinámicas urbanizadoras han ido adoptando un carácter cada vez más disperso o en mancha de aceite, generando la llamada "ciudad difusa", "ciudad estallada", o urban sprawl, y provocando un impacto territorial sin parangón en la historia de la Humanidad sobre el planeta Tierra (Naredo, 2000; Davis, 2005; Fdez Durán, 2006).

En su expansión y propagación a lo largo del siglo $\mathrm{XX}$, la forma metrópoli se manifestó en la primera mitad del siglo especialmente en los países centrales, y muy en concreto en Occidente. Las principales metrópolis en 1900 eran Londres y París, seguidas de cerca por Nueva York. La "ciudad vertical" por excelencia, que irrumpía con fuerza por aquel entonces. Esta "ciudad vertical" que luego se iría extendiendo en menor medida por los espacios centrales y que implicaba un intenso consumo energético eléctrico (de procedencia principalmente fósil) para garantizar la movilidad vertical de sus habitantes. La demanda de energía eléctrica se dispararía activada además por la extensión de la iluminación artificial urbana y la extensión de la segunda revolución industrial. En la segunda mitad del siglo, en cambio, la forma metrópoli va a proliferar especialmente en el Sur y en concreto en los Estados periféricos emergentes del nuevo capitalismo global, y muy en concreto en China e India, como resultado de diversos factores: industrialización, fuerte desarticulación del mundo rural y explosión demográfica. Pero este proceso está marcado en general por una urbanización de carácter dependiente de las dinámicas centrales. De entre todos los creci- mientos urbanometropolitanos cabe destacar el caso de China, donde desde hace casi tres décadas se está dando el mayor proceso de migración de masas y de urbanización que el mundo haya conocido jamás, con centenares de millones de personas migrando en este periodo desde el interior del gigante asiático hacia las metrópolis de su fachada del Pacífico (Harvey, 2007).

Todo ello ha hecho que las principales "Megaciudades" del mundo en términos demográficos se encuentren hoy en día en general fuera de los espacios occidentales, y que las dos principales metrópolis de principios del XX, Londres y París, a pesar de su fuerte crecimiento durante el siglo, hayan sido desplazadas bruscamente al puesto 23 y 26 del ranking mundial, respectivamente. En la actualidad el grueso del crecimiento urbanometropolitano desde el punto de vista demográfico tiene lugar en el Sur, y fundamentalmente en torno al Pacífico y al Índico, en el Este y Sudeste de Asia (ver figura 2) (www.citypopulation.de). Sin embargo, aunque las principales metrópolis centrales no ocupen ya muchas de ellas los primeros lugares del ranking en cuanto a población, si se siguen manteniendo por supuesto en cabeza (todavía) en cuanto a importancia económica y sobre todo financiera. Además, no son para nada comparables las grandes metrópolis del Centro y las Megaciudades periféricas, pues en estas últimas más de la mitad de su población en muchos casos vive hacinada en situaciones de absoluta miseria, en tejidos urbanos enormemente degradados y sin ningún tipo de servicios. Más de 1000 millones de personas, de los más de 3000 millones que habitan en áreas urbanas en el mundo, viven en esos gigantescos tejidos de infravivienda, habiendo sido expulsadas la gran mayoría de ellas hacia las Megaciudades periféricas por la "modernización" forzada del mundo rural. En algunos casos, como en Colombia, manu militari. En definitiva, este mundo crecientemente urbani- 
zado es a su vez, cada vez más, un planeta de "Ciudades Miseria", como nos recuerda Mike Da- vis (2005).

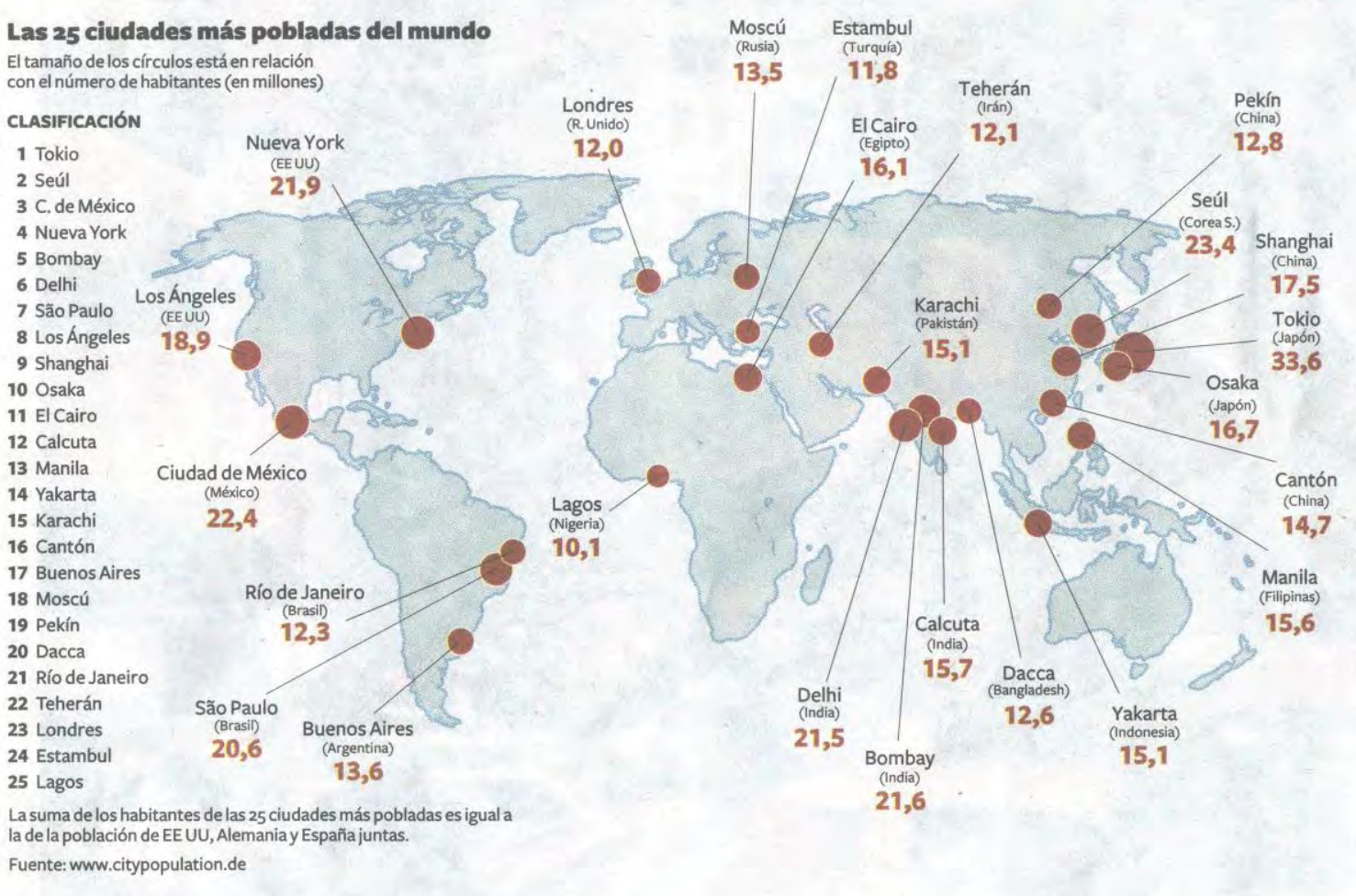

Figura 2. Las 25 ciudades más pobladas del mundo. http://www.citypopulation.de.

Pero también se dan otras importantes diferencias entre los territorios del Centro y de la Periferia del nuevo capitalismo global. En los espacios centrales en torno a las $4 / 5$ partes de su población habita en áreas urbanas, teniendo una muy baja población empleada agraria (menos del 3\% en EEUU, algo superior al 5\% en la UE, y algo similar acontece en Japón). Además, como ya hemos apuntado, la agricultura que se da en estos espacios centrales es casi en su totalidad una agricultura sin campesinos, altamente industrializada, que utiliza una mano de obra inmigrante, en muchos casos clandestina o "ilegal", en condiciones de hiperexplotación y semiesclavitud. En los espacios periféricos sin embargo la situación es enormemente diversa. Así, tenemos desde Estados agroexportadores como Argentina o Brasil con porcentajes de población urbana parecidos a los espacios centrales, en torno a un $80 \%$ del total, con gran presencia del agrobusiness, a grandes Estados como India y China que a pesar de su fortísimo crecimiento urbano todavía más de la mitad de su población habita en el mundo rural tradicional. Si bien este mundo está siendo fuertemente desarticulado y se ve cada vez más afectado por la agricultura industrializada. $\mathrm{Y}$ finalmente, existen aún espacios periféricos en Asia, África y en menor medida América Latina, donde una amplia mayoría habita todavía en los mundos campesinos e indígenas que sobreviven. Este es el mapeo a brocha gorda de los procesos de urbanización en el mundo. De cualquier forma, es conveniente resaltar que los procesos de urbanización no se producen de forma natural, sino que son impulsados desde las estructuras de poder, están activados por la lógica del mercado (mundial, regional y estatal) que los promueve, están condicionados por las dinámicas territoriales y poblacionales históricas previas sobre las que operan, y son tributarios de un enorme con- 
sumo de energía fósil, que es el que los hace factibles (Fdez Durán, 2006 y 2008).

¿Pero cuál es la estructura (o estructuras) que ha ido adoptando la forma metrópoli a lo largo del siglo pasado, cuáles han sido los principales elementos que han condicionado su despliegue, qué papel ha cumplido la nueva movilidad motorizada en la expansión de lo urbano, y muy en concreto el vehículo privado y el transporte por carretera, y cómo se ha producido la progresiva mercantilización de la vivienda y el espacio urbano, que ha permitido que la metrópoli se convierta en un elemento central en los procesos de acumulación de capital? La respuesta a estas cuestiones nos pueden permitir entender su fuerte crisis actual, y la más que previsible profundización de la misma debido a la crisis global y multidimensional en marcha: financiera, económica, energética, alimentaria, climática y ecológica, así como de hegemonía de EEUU y Occidente.

\section{El automóvil, elemento clave en la configuración de la metrópoli del siglo $\mathrm{XX}$}

La aparición del automóvil ya se había producido como hemos dicho a finales del siglo XIX, pero hasta principios del siglo XX permanecería como un artefacto de lujo, de uso y disfrute de las clases dominantes occidentales. Sin embargo, su poder de seducción iba a ser enorme para el conjunto de las sociedades. La velocidad, aceleración, movilidad, flexibilidad, autonomía (en base, eso sí, al petróleo) y libertad que caracterizaban a este nuevo medio de transporte, así como su ligazón con los sectores más poderosos de las sociedades por las que iniciaba su caminar, suscitó deseos, sueños y envidias desde el primer momento, provocando un fuerte impacto en el imaginario colectivo. El coche además nos remitía a nuestro pasado nómada, fomentando la posibilidad de no estar atado a un territorio concreto, y permitía disfrutar de las ansias de movilidad y del éxtasis de la conducción y la velocidad a los elegidos.

Pero no sería hasta la segunda década del siglo pasado cuando se produce un verdadero salto cualitativo en su repercusión social, a partir de su producción en masa y en cadena bajo el comando de Henry Ford en EEUU en 1913. La trascendencia de ese punto de inflexión histórico es difícil de valorar en todas sus dimensiones y complejidad. La producción industrial, la extracción petrolífera, la ciudad y el territorio, y en definitiva la sociedad estadounidense, algo más tarde el resto de las sociedades occidentales y después gran parte del mundo entero, se puede decir que ya no volverían a ser los mismos. Aparecía poco a poco una nueva clase obrera, primero en EEUU y posteriormente en otros espacios centrales, capaz de acceder a un bien hasta entonces de lujo. Henry Ford decía que había que pagar a sus operarios para que pudieran comprar los coches que ellos producían (eso sí, endeudándose), y que eso iba a generar un nuevo tipo de ciudadano. Ford manifestaba que él "no sólo producía coches, sino también personas". Se iniciaba pues lo que luego se consideraría el "fordismo". Y el petróleo y el automóvil se convertirían en dos elementos trascendentales para asentar la progresiva hegemonía económica de EEUU; de hecho, el petróleo sustituiría al carbón como principal fuente energética en su sistema transporte en 1930. Algo más tarde, de este lado del Atlántico, Hitler, que llegaría a condecorar a Ford, se extasiaría con el lanzamiento del Volkswagen (“El coche del pueblo", de su pueblo elegido), que intentaba emular en Europa la hazaña del magnate estadounidense (Varela, 2008; Los Amigos de Ludd, 2008).

Se consolidaba por tanto la imbricación del ser humano con la máquina, generando un nuevo Yo ampliado, un nuevo centauro moderno, con tubo de escape. El automóvil se iba a convertir en un elemento trascendental de la Megamáquina que 
caracteriza a la antroposfera industrializada. Lo cual iba a ser a su vez el germen de una sociedad crecientemente individualista, consumista y urbana. La nueva religión en torno al dios automóvil estaba ya definitivamente en marcha, y la industria que iba a marcar todo el devenir del siglo $X X$ irrumpía con especial fuerza, no en vano su producto gozaba ya de una amplia aceptación social. El vehículo privado se iba a transformar paulatinamente en una pieza central de la cotidianeidad de las sociedades occidentales (Varela, 2008). Todo ello iba a afectar sin duda a la concepción de la ciudad, y sobre todo a los planes sobre su futuro y obligado crecimiento. De esta forma, en paralelo a la irrupción del automóvil como fenómeno de masas, es decir desde la segunda década del siglo $\mathrm{XX}$, irrumpe también el llamado Movimiento Moderno en el urbanismo, promovido por las llamadas vanguardias europeas y estadounidenses, una de cuyas máximas figuras sería Le Corboussier. Un movimiento que va a impulsar un nuevo orden para el futuro de la ciudad, lo que iba a tener una enorme trascendencia. El movimiento se proponía acabar con el orden irracional de la ciudad tradicional, caótico, sombrío, sucio, etc., y sobre todo promulgar un nuevo orden homogéneo e isótropo dominado por la velocidad, donde pudiera desenvolverse sin trabas el nuevo artefacto civilizatorio: el automóvil, que manifestaba ansias de proyección global. Además, en 1927 Lindberg lograría cruzar por primera vez en avión el Atlántico, lo que impulsaría decisivamente la aviación comercial en los años 30. Este nuevo medio de transporte, basado también en el uso de los derivados del petróleo, sería con el tiempo otro elemento central de proyección mundial de la Modernidad occidental. De esta forma, este nuevo Orden Moderno sería bienvenido tanto en las sociedades capitalistas, fueran éstas "democráticas", autocráticas o totalitarias (nazismo, fascismo), y hasta en las nuevas sociedades "comunis- tas”, en tránsito hacia el totalitarismo. La ciudad histórica se iba a convertir poco a poco en un anacronismo disfuncional para la nueva movilidad y las nuevas sociedades, sin interés para su conservación ante la nueva valoración de lo Moderno (Verdaguer, 1998). Y la percepción del territorio, y de sus escalas, se iba a ver bruscamente alterada por el salto sin precedentes que experimentaba el transporte motorizado en cuanto a la velocidad.

Todo ello se iba a plasmar definitivamente en el nuevo urbanismo racionalista de la llamada Carta de Atenas, en 1933, promulgada por el Congreso Internacional de Arquitectura Moderna (CIAM), donde se establecían las bases para el urbanismo del futuro: una nueva ciudad ordenada, limpia y segmentada física y socialmente, en ruptura definitiva con la ciudad tradicional, que no importaba que engullera el territorio circundante y que arrasara con las formas agrícolas que le daban vida. Así, se propugnaba la separación estricta de las distintas funciones urbanas en el espacio, en para cada una de ellas. El habitar sería un espacio fundamentalmente femenino, el trabajar fundamentalmente masculino, el recrearse incluiría también poco a poco la actividad comercial, y el circular estaría garantizado por vías de alta capacidad. Así, entre las distintas funciones resaltaba la importancia del espacio dedicado a la actividad de transportarse, que era además la que interconectaba todas las demás, estableciéndose una red amplia e isótropa para el automóvil y el transporte por carretera en general. Por otro lado, la Carta de Atenas se hacía eco de dos cuestiones adicionales. Una, el nuevo habitar urbano iba a estar crecientemente marcado por la familia nuclear como célula básica de la sociedad, con nuevos hábitos de alimentación y consumo, y crecientemente equipada por electrodomésticos, sentenciando el fin del hogar de la familia extensa y autosuficiente, lo que se acabaría convirtiendo en una trampa para las mujeres. $\mathrm{Y}$ dos, que el 
estilo arquitectónico que iba a predominar abiertamente a partir de entonces sería el llamado Estilo Internacional o Universal. Formas puras y simples ajenas a todo avatar climático y a toda veleidad localista. De esta forma, se sentaban las bases para la extensión imparable de las nuevas formas de lo Urbano, y por extensión de lo Social, un programa supuestamente aplicable a todos los rincones del planeta (Vega, 2004 y 2007, Verdaguer, 1998; Choay, 1994).

Este nuevo programa urbano se iba a aplicar con fuerza en EEUU, pues allí la ciudad tradicional apenas era una rémora, y por lo tanto se pudo llevar a cabo con menos cortapisas. Sin embargo, el Nuevo Mundo anglosajón se va a ir decantando paulatinamente hacia un urbanismo de menor densidad en sus periferias metropolitanas, debido al fuerte influjo del automóvil y al creciente predominio de la vivienda unifamiliar de promoción privada, sobre todo con posterioridad a la Segunda Guerra Mundial (Mumford, 1963). Este urbanismo de baja densidad de los "Suburbia", sería el espacio donde se intentaría vanamente plasmar el American Dream por parte de sus "clases medias", y se convertiría en una especie de jaula de oro para las mujeres, atrapadas en la trampa de una nueva y "deslumbrante" esfera doméstica, fuertemente consumidora de energía. Mientras tanto, en los centros terciarios de sus metrópolis iba a prevalecer la construcción de gran altura, y en concreto los rascacielos, que ya habían despuntado en Nueva York desde principios de siglo. Y cerca de ellos, se iban a ir generando guetos de población negra, en muchos casos de vivienda pública, ante la huida de la clase media hacia la periferia metropolitana. Por otra parte, en las periferias de las metrópolis europeas se aplicaría también este nuevo programa urbano con intensidad ya después de la contienda, para hacer frente al intenso crecimiento demográfico y urbano de los años 50 y 60, así como hasta en el propio interior de la ciudad histórica en la labor de reconstrucción de las importantes áreas dañadas por la guerra, proliferando en todos ellos los espacios urbanos de bloque abierto en altura hasta los años 70. En Europa occidental gran parte de la construcción de vivienda en este periodo de los "Treinta Gloriosos" fue de carácter público, como parte importante de la construcción del Estado del Bienestar.

Pero este programa urbano también presidiría como apuntábamos el espíritu del "urbanismo socialista" en el Bloque del Este, en el intenso crecimiento urbano que se dio como resultado del proceso industrializador y modernizador feroz que tuvo lugar durante el periodo de construcción del "Socialismo en un Solo País", si bien el papel que desempeñó el automóvil fue muy inferior al que tuvo lugar en Occidente. Un "urbanismo socialista" marcado por la enorme homogeneidad y fealdad de la producción en masa "socialista" (valga la redundancia), que abandonaba a su propia suerte a la ciudad histórica tradicional. En China el crecimiento urbano fue más contenido durante el periodo de Mao Tse Tung, y de hecho durante la Revolución Cultural se revertió o frenó en parte, aunque de hecho ya partía de importantes ciudades con un amplio recorrido histórico. Pero el espíritu del "urbanismo socialista" chino fue parecido, aunque la movilidad urbana estuvo principalmente garantizada por los medios no motorizados, y muy en concreto por la bicicleta. Por último, en el denominado "Tercer Mundo", dentro de su gran diversidad, el nuevo urbanismo iría poco a poco complementando y sustituyendo a las morfologías coloniales y postcoloniales (en América Latina) de origen decimonónico, en aquellas partes de las ciudades donde predominaba la economía formal, y donde se localizaban los centros de poder y las clases asentadas. Si bien, como ya hemos apuntado, el crecimiento principal de las nuevas metrópolis periféricas 
estaba siendo determinado ya por una avalancha informe de tejidos urbanos autoconstruidos y sin infraestructuras de ningún tipo. $Y$ en estos espacios urbanos de la Periferia la movilidad motorizada cumplió también un papel poco relevante hasta los años 70 (Kotkin, 2006).

\section{Metrópoli, acumulación de capital y expansión del mercado}

A nadie se le escapa el hecho de que si la nueva metrópoli triunfó fue porque era funcional a los intereses de expansión y reproducción del capital, aunque se plasmara con formas distintas en los diferentes territorios del planeta, pues si no, no se hubiera impuesto como forma urbana hegemónica a lo largo del siglo pasado. Por una parte, la metrópoli era la estructura espacial construida capaz de atraer inversiones industriales en ascenso, una vez que éstas se independizaban definitivamente de su localización cercana a los yacimientos de energía y materiales debido a los avances del transporte motorizado en general, y en especial del transporte por carretera; así como a la reducción de los costes respectivos debido a la abundancia de combustibles fósiles, y en concreto al petróleo barato. Por otra parte, la metrópoli era también la forma espacial que atraía una masa obrera asalariada en ascenso, debido a la creciente desarticulación del mundo rural y a las oportunidades de trabajo asalariado que ofrecía. Pero al mismo tiempo la metrópoli hacía posible la reducción del coste de reproducción de la fuerza de trabajo, debido al abaratamiento de los costes de vivienda, comida y transporte. En este sentido, la energía barata fue esencial para reducir asimismo todos esos costes. Todo lo cual convirtió a la metrópoli en el espacio idóneo para la producción industrial, posibilitando importantes economías de escala y aglomeración para el capital.

Igualmente, el crecimiento urbano en general, y el metropolitano en particular, permitía el desarrollo creciente de la economía monetarizada. A principios del siglo XX ya nos recalcaba Simmel (1990) cómo la metrópoli era el reino de la expansión de las relaciones mercantiles y del dominio creciente del dinero en las relaciones humanas. Lo cual era una forma de expansión del mercado y de la lógica del capital en la vida cotidiana. Máxime conforme el tamaño de la metrópoli aumentaba, y el grado de especialización y de división del trabajo se acrecentaba. De esta forma, muchas de las actividades que antes se realizaban al margen de la economía monetaria, pasaban poco a poco a adoptar un componente mercantil. Asimismo, el consumo empezaba a tener una creciente dimensión financiera, con la aparición del crédito al consumo, sobre todo en las metrópolis centrales. Lo cual era especialmente cierto con la expansión de la motorización privada, hecho que reforzaba a su vez el dominio del dinero en las grandes conurbaciones.

Por último, la propia construcción de los espacios urbano-metropolitanos se convertía en un campo de acumulación de capital. Por un lado, porque la construcción habitacional pasó a estar cada vez más dominada por la lógica del mercado, cosa que en general no era así en el siglo XIX, cuando la autoconstrucción estaba muy extendida dentro de las llamadas "clases peligrosas", así como el habitar colectivo. Ahora, el proceso de construcción de viviendas (mediado o no por el Estado) se convertía en un nuevo campo de acumulación de capital, con tecnologías crecientemente industrializadas. Y esta dinámica se reforzaba aún mucho más de cara a la construcción de infraestructuras, necesarias para la expansión de los espacios urbano-metropolitanos, y la interconexión entre los mismos, en donde el papel desempeñado por el Estado fue además determinante. Todo ello reforzaba a una industria de la construcción que se iba a convertir con el paso del siglo en uno de los principales sectores de acumulación de capi- 
tal, demandante a su vez de gran número productos manufacturados. De hecho, después de la Segunda Guerra Mundial la reconstrucción y fuerte expansión de las conurbaciones, más la creación de una vasta red de autovías y autopistas, urbanas e interurbanas, fue uno de los sectores clave de acumulación de capital en los países centrales (Harvey, 2007) ${ }^{3}$. En los Estados centrales las metrópolis se van convirtiendo en espacios clave de acumulación de capital, y los valores del suelo y del espacio edificado se establecen claramente a partir de la división técnica y social del espacio urbano, y en torno a un valor determinante: la centralidad. Finalmente, la propia metrópoli se configuraba como el espacio idóneo para la especulación urbana, y actuaba como atractora por lo tanto de capitales sin escrúpulos que buscaban beneficios abultados y rápidos.

\section{El impacto de la nueva metrópoli sobre el territorio y la propia ciudad}

El despliegue de la forma metrópoli iba a tener diferentes clases de impactos. A nivel local los podríamos caracterizar de dos tipos. Por un lado, sobre el territorio en el que tiene lugar ese despliegue, y por otro, sobre la misma ciudad a partir de la cual se activa el crecimiento metropolitano, así como las transformaciones que experimenta la propia esencia de la ciudad en este nuevo espacio urbano ampliado, difuso, fragmentado y estallado. La metrópoli en su crecimiento engulle los diversos lugares del territorio fruto de un diálogo de siglos entre los seres humanos y la naturaleza, que expresan la cultura territorial o espacial de larga duración. Distinta en cada parte del mundo, y dependiente también de las características socio-políticas, culturales, climáticas, bióti-

3 La construcción de grandes infraestructuras se llevaría a cabo en algunos casos vía presupuestos generales del Estado (caso de la RFA, p.e.), a través de fórmulas de peaje privadas o públicas (caso de Italia y Francia), o mediante tasas finalistas (caso de EEUU y su extensísimo Interstate Highway System), o mediante una combinación de estas fórmulas. cas y paisajistas. Al deglutir y alterar los lugares sobre los que se despliega, la metrópoli rompe la relación con la historia y acaba con la memoria que se almacena en el territorio. Quiebra pues el lazo cultura local-naturaleza, arrasando formas territoriales de mayor complejidad local, identidad y sostenibilidad. La metrópoli por tanto se asienta sobre un nuevo territorio bruscamente alterado y artificializado, pero ya no depende de él, como la ciudad histórica para su abastecimiento diario, sino que su funcionamiento vital viene garantizado por recursos alimenticios, materiales y energéticos de territorios cada día más lejanos, aparte de por capitales y personas crecientemente foráneos. De esta forma, la "Segunda Piel" (o antroposfera) que se desarrolla sobre la naturaleza (o "Primera Piel") desde el neolítico, da un salto cualitativo de gigante con la aparición de la forma metrópoli, rompiendo amarras con los vínculos que ligaban la ciudad histórica al territorio, que ya se habían visto fuertemente alterados con la "ciudad industrial" del XIX (Magnaghi, 2003).

Por otra parte, la propia ciudad va a experimentar también una transformación radical. En un siglo ha habido una verdadera mutación de la misma, enmascarada por lapermanencia de las palabras y los topónimos que designaban la urbe tradicional, pero que a duras penas logra ocultar la fuerte transformación acontecida en la ciudad histórica, que va a acabar paulatinamente convertida en un parque temático turístico y comercial; y hasta induce una importante metamorfosis en la propia ciudad burguesa e industrial del XIX. Quizás el cambio más importante acontecido en ambos tejidos es la progresiva transformación y muerte de la calle como espacio público ciudadano de convivencia y comunicación, como resultado principalmente de la irrupción del automóvil y el transporte público en superficie. Lo cual va a derivar en un acusado deterioro del espacio público ciudadano. Más allá de estos tejidos urbanos 
premetropolitanos, en la nueva "ciudad difusa o estallada" que implica el nuevo crecimiento metropolitano, lo que predomina son piezas monofuncionales urbanas (residenciales, industriales, comerciales, terciarias...) interconectadas por una red viaria de alta capacidad crecientemente amplia y compleja, pues el nuevo desarrollo es altamente dependiente del vehículo privado y el transporte por carretera. Este nuevo territorio artificializado está plagado de lo que Marc Augé (1993) ha denominado No-Lugares (gasolineras, grandes centros comerciales, centros y estaciones de transporte, aeropuertos, etc.), espacios urbanos sin identidad, donde predomina el anonimato, el desarraigo, la incomunicación y la desterritorialización. En este nuevo territorio donde impera Lo Urbano, pero que es la No-Ciudad, el espacio principal se dedica a la función de transportarse, dominada por el automóvil, pero curiosamente desaparece la calle como espacio público por excelencia, y por supuesto el transporte peatonal (Choay, 1994). En suma, como nos dicen Estevan y Sanz (1996):"Las consecuencias del automóvil en la ciudad son las de una „,omba" lenta, una „bomba" cuya onda expansiva tuviera la virtud de trasladar edificios y actividades a varios kms a la redonda, y cuyo principal efecto en el interior fuera el de destruir la propia esencia de las urbes: la convivencia y la comunicación de los seres humanos".

Pero el automóvil va a acabar pronto muriendo de su propio éxito. Su éxito es su propio fracaso. Primero en las metrópolis estadounidenses, luego en las europeas y occidentales en general, y más tarde en las del mundo entero, conforme su presencia y actuación indiscriminada las va afectando a todas ellas. Las metrópolis estadounidenses son las primeras que se empiezan a configurar a partir del automóvil, ya antes de la Segunda Guerra Mundial. Lo cual se profundiza después de la contienda con el creciente desmantelamiento de los transportes públicos como tranvías y ferrocarriles, propiciado por la propia industria del automóvil y petrolera; siendo reemplazados solo en parte por los autobuses de la industria de Detroit, la capital de los reyes del transporte por carretera. En esos años se acuñaría el dicho de que "lo que es bueno para la General Motors es bueno para EEUU". Y todo ello es engrasado por la "industria" de la publicidad, que fabricaba al mismo tiempo compradores. El ejemplo más característico de este modelo sería Los Ángeles, la primera metrópoli del mundo construida ex novo en torno al automóvil, con muy bajas densidades y grandes infraestructuras viarias que incentivan a su vez una mayor dispersión urbana (Mumford, 1963). Pero muy pronto se verían los límites de este falso sueño de movilidad motorizada privada para el conjunto de la sociedad, que ni es universal ni es equitativo, pues margina a determinados sectores de edad (niños y ancianos), a mujeres y a ciertos grupos étnicos. Pero eso sí, la sociedad entera se acaba convirtiendo en tributaria del transporte motorizado privado no solo para los desplazamientos ocasionales, sino para los desplazamientos cotidianos. Por primera vez en la historia. Empieza a aparecer la enfermedad del transporte a la que, como resultado de los niveles de congestión alcanzados y de las distancias a recorrer, el estadounidense medio acaba dedicando una cuarta parte del tiempo social disponible, mientras que a principios del siglo $X X$ no era más del $3 \%$ al $8 \%$. Pasado cierto límite, la industria de la velocidad cuesta más tiempo a la sociedad y al ciudadano del que en teoría ahorra, aparte del coste económico y social que supone (Illich, 1974). Además, el espacio urbano dedicado a la movilidad acaba adquiriendo porcentajes absolutamente patológicos. En el caso de Los Ángeles el $60 \%$ del espacio construido está dedicado al transporte viario (Fdez Durán, 2000).

La metrópoli europea se acabaría construyendo a 
partir de las relevantes ciudades burguesas e industriales del siglo XIX, y manifestaron en su primer despliegue una diferencia considerable con sus contrapartes estadounidenses, principalmente en lo que a su densidad y movilidad motorizada privada se refiere. Lo mismo cabría manifestar respecto de la metrópoli japonesa. Sus densidades fueron siempre bastantes más altas que las metrópolis de EEUU, salvo quizás en sus áreas centrales, y lo mismo podemos decir en cuanto a sus sistemas de transporte colectivo, que tuvieron un mayor desarrollo que en el Nuevo Mundo anglosajón (exceptuando el caso de Nueva York y Chicago); sobre todo en lo que respecta al transporte colectivo subterráneo (tipo metro), pero también en cuanto al transporte colectivo de superficie, y hasta en lo relativo al transporte peatonal y en bicicleta. Ello fue así porque también la intervención estatal en cuanto a su planeamiento fue importante, al menos hasta finales de los años 70. Es por eso por lo que su dispersión sobre el territorio aunque importante fue más contenida, y los espacios públicos ciudadanos, la plaza y la calle, resistieron en parte a la avalancha del automóvil. Aun así, la enfermedad del transporte acabó alcanzando también a las metrópolis europeo-occidentales y japonesas, al poco de que se generalizara la producción en masa del automóvil, en los años 50 y 60 . Es decir, hasta los 70, años de las primeras crisis petrolíferas. Las sociedades europeas occidentales y nipona también se convirtieron en tributarias del transporte motorizado privado, pero nunca alcanzaron el grado de dependencia del automóvil que desarrolló la sociedad estadounidense, y en menor medida otras partes del mundo anglosajón (Canadá, Australia, Nueva Zelanda).

\section{La repercusión lejana y global de la metrópoli}

De cualquier forma, la metrópoli de los países centrales estaba teniendo un impacto muy consi- derable más allá de los territorios sobre los que se desplegaba. Primero, porque ese despliegue era como hemos dicho difuso y no tenía unas fronteras definidas, como la ciudad histórica o hasta la propia ciudad industrial del XIX. En la metrópoli moderna es muy difícil determinar donde acaba la "ciudad" y dónde empieza el "campo", la nueva "urbe" se difumina por el espacio sin una solución real de continuidad. Además, la propia construcción de la metrópoli reclama materiales de un entorno cada vez más extenso, provocando importantes heridas al territorio (canteras, graveras, etc.) al tiempo que expulsa determinadas actividades no queridas a distancias cada vez más lejanas (vertederos, p.e., debido a la explosión de residuos urbanos consecuencia de las nuevas formas de consumo y de vida). Pero, además, el impacto o la influencia de la metrópoli se prolonga a través de las nuevas vías de alta capacidad (autopistas y autovías) que cada vez más la interconectan con otros congéneres, y que prolonga su influencia en un radio cada día mayor dentro del mundo rural próximo y distante, sirviendo estos canales (junto con los nuevos medios de comunicación de masas) para difundir las dinámicas del mercado, los valores urbanometropolitanos, y hasta los No-Lugares ya mencionados por un territorio cada vez más amplio. El campo se empieza a ver como algo exótico desde las áreas de descanso de las autopistas. $Y$ era por estas vías también por donde empezaba a viajar el nuevo ciudadano nómada metropolitano, que tan bien caracterizó Jack Kerouac en los 50 en su célebre novela "On the Road" ("En la carretera"). Una nueva generación que canalizaba sus ansías de movilidad y libertad mediante el uso creciente del automóvil, en el espacio interurbano donde en principio no había congestión, movido por los "esclavos energéticos" que le proporcionaba el petróleo. Ese sería el origen del NowhereMan o de la Nowhere-Woman que se iría desarro- 
llando más tarde con fuerza en todos los espacios centrales; es decir, del ser humano desterritorializado, o sin raíces.

Igualmente, para que la metrópoli funcionara era preciso garantizar el abastecimiento de recursos hídricos, a través de infraestructuras de captación y transporte cada vez más lejanas y complejas, y progresivamente instalar el tratamiento de sus efluentes para reducir el impacto ambiental, y eliminar la insalubridad interna que tanto daño había hecho a la primera "ciudad industrial", hasta ya entrada la segunda mitad del XIX. Todo lo cual requiere una considerable energía para su funcionamiento.

Lo mismo cabe apuntar en cuanto al abastecimiento de energía eléctrica, que se garantizaba mediante plantas de generación en ocasiones a centenares de km de las metrópolis, en ese intento de alejar de la misma las actividades más impactantes y contaminantes. Pero es preciso resaltar que para el funcionamiento diario de la metrópoli, como hemos señalado, es preciso garantizar el aporte de recursos energéticos fósiles y materiales (entre ellos, los propios alimentos) de territorios cada vez más lejanos, en muchos casos transcontinentales, y que ello gravita sobre redes de transporte intermodales de indudable complejidad y que consumen asimismo abundante energía fósil. De esta forma, el sistema urbanometrópolitano se materializa como un sistema cada vez más complejo de redes materiales ( $\mathrm{y}$ progresivamente inmateriales), crecientemente energívoro, de una proyección e impacto cada vez más global. La huella ecológica de la metrópoli se va extendiendo pues poco a poco al planeta entero.

Pero esta primera etapa de expansión de la forma metrópoli a escala mundial, que había alcanzado prioritariamente a los países centrales, y que es especialmente importante durante los "30 Gloriosos", se frena bruscamente con ocasión de las crisis energéticas de los setenta, la paralela crisis del fordismo y el keynesianismo, y la fuerte subida de los tipos de interés de final de la década y primeros de los 80 . Durante casi diez años (1973-83) los procesos de urbanización prácticamente se paralizan en el sistema urbano superior de los espacios centrales occidentales, a causa de la quiebra del crecimiento económico, de la consiguiente crisis productiva, de la crisis inmobiliaria y de la crisis fiscal del Estado, que es particularmente intensa en las metrópolis, caso de Nueva York, p.e. (Harvey, 2007); al tiempo que la expansión de la movilidad motorizada se refrena sustancialmente, decayendo en ocasiones. De cualquier forma, las dinámicas de metropolitanización continúan con sordina en los espacios periféricos en los 70 , animadas en algunos casos, como en los países OPEP y otros extractores de petróleo, por el chorro de petrodólares proveniente de los países centrales (Caracas, México DF o Yakarta, son buenos ejemplos de ello), o bien por el reciclaje de los mismos petrodólares hacia los países periféricos. Petrodólares que van a parar a megaproyectos infraestructurales, así como a la paralela desarticulación del mundo rural, a través de la expansión de la agricultura industrializada, todo ello en nombre del "Desarrollo". En cualquier caso, el fuerte crecimiento demográfico que toma cuerpo en todos los Estados de la Periferia repercute asimismo en el despegue del estallido de sus Megaciudades.

\section{La lengua de lava metropolitana se reactiva con la "globalización" y la energía barata}

A principios de los 80 , con la caída de los precios del petróleo ya comentada y la paralela reducción de los tipos de interés del dólar ( $y$ del resto de las divisas centrales), así como la también paralela aplicación de las políticas neoliberales y la creación de un nuevo capitalismo global (privatización, desregulación, apertura de las economías nacio- 
nales al mercado mundial, impulso de mercados regionales planetarios, financiarización, etc.), la lengua de lava metropolitana resucita con gran intensidad tanto en el Norte como especialmente en el Sur. En los países del Este se vería bruscamente frenada en los 90 por el colapso de la URSS y su área de influencia en esos años, retomando poco a poco el vuelo en este nuevo siglo. Pero en China, como hemos apuntado, la urbanización sería especialmente intensa desde el cambio de rumbo que supone su progresiva integración en el nuevo capitalismo global a partir de los ochenta. Esta fuerte dinámica urbanizadora a escala mundial va a durar casi treinta años, durante la nueva etapa de energía barata, es decir, hasta el reciente agravamiento de la crisis energética. Es más, se va a agudizar en los primeros años del nuevo milenio, debido fundamentalmente al recrudecimiento de la financiarización de las economías, y como consecuencia de ello al desarrollo de una potente burbuja inmobiliaria de importante dimensión global. Una burbuja inmobiliaria que está estallando desde el verano de 2007, precipitando la crisis del sistema financiero mundial, y viceversa, pero sobre esto último hablaremos más adelante.

En estos últimos 30 años, como ya hemos señalado, la forma metrópoli en su renovado despliegue va a adoptar por así decir dos nuevas versiones, la "Ciudad Global" en los espacios centrales y la "Megaciudad Miseria" en la Periferia, coincidiendo en parte ambos fenómenos en algunas grandes conurbaciones de los nuevos Estados "emergentes". Por otro lado, el crecimiento de la forma metrópoli va a adquirir en muchos casos una nueva proyección espacial, mediante la creación de regiones metropolitanas, llegando a alcanzar en ocasiones una aún mayor dimensión con la aparición de las Megalópolis. Esto es, la interconexión de diversas metrópolis en un vasto espacio regional. Veamos con algo más de deta- lle algunas características de estos procesos, pues su conocimiento va a ser determinante para entender el impacto territorial que va a tener en el futuro la crisis energética mundial en marcha.

La expansión de la Segunda Piel urbanometropolitana se va a poner pues de nuevo en marcha arrasando aún más los distintos territorios mundiales sobre los que se despliega, en un proceso incontrolado de urbanización planetaria. Se refuerzan las dinámicas de litoralización (hacia las fachadas marítimas), meridionalización (hacia las zonas de climas benignos) y "Ilanificación" (hacia las áreas más accesibles y menos accidentadas) del crecimiento de lo Urbano, y su desarrollo a lo largo de los ejes de transporte de gran capacidad y vías fluviales, sobre todo en los espacios centrales, generando un desarrollo aún más difuso que en la etapa anterior, que se desenvuelve en muchas ocasiones sobre espacios agrícolas de indudable valor. Podríamos afirmar, siguiendo a Heinberg (2006), que ahora Los Angeles está estallando en todo el planeta, al igual que la explosión de los No-Lugares (Verdaguer, 1998). Además, este estallido desordenado de los tejidos urbano-metropolitanos se ve favorecido porque el planeamiento de la ciudad ha sido abandonado casi completamente como proyecto integrador y consciente, convirtiéndose cada vez más en un automatismo del mercado. Incluso en la UE, el espacio mundial que ha tenido mayor regulación urbanística. Por otro lado, el crecimiento urbanometropolitano va a desbordar en muchos casos las fronteras estatales, como resultado de la creciente preponderancia de las dinámicas del mercado mundial, o de los mercados regionales planetarios (UE, TLC, MERCOSUR, APEC, etc.). EI caso de las llamadas Euro-regiones en muchos de los territorios transfronterizos de Europa Occidental es un ejemplo de ello.

En muchas ocasiones se producen importantes desarrollos urbano-metropolitanos en torno a las 
fronteras estatales, sobre todo allí donde existen bruscas discontinuidades de riqueza, así como de los mecanismos de control y regulación (caso p.e. del borde entre EEUU y México). $O$ bien en las llamadas Zonas Económicas Especiales, territorios donde no se aplica la legislación nacional (impuestos, regulación laboral, normativa ambiental...) y que son los espacios preferidos para la localización de las maquilas y plantas industriales de la nueva Fábrica Global. Pero igualmente asistimos en este periodo a una importante urbanización de los llamados Paraísos Fiscales, la pata alegal (indispensable) del funcionamiento de las finanzas globales. Aunque el dinero tenga una dimensión fundamentalmente inmaterial, requiere de espacios materiales altamente sofisticados donde se lleva a cabo de forma prioritaria la especulación financiera, la evasión fiscal y el lavado del dinero negro. Estos Paraísos Fiscales forman pues parte determinante del Casino Global, y hasta son apoyados por fondos comunitarios en algunos casos para la realización de sus infraestructuras de conexión. Caso por ejemplo del aeropuerto de las Islas Caimán, que ha disfrutado de ayudas comunitarias (Hernández Vigueras, 2008).

Por otro lado, la creciente preponderancia en este periodo del transporte por carretera, hace que el impacto de lo Urbano, y en definitiva de la lógica del capital y del mercado, penetre aún mucho más en los distintos territorios planetarios. En este sentido, y siguiendo a Barreda (2008), es curioso comparar las redes ferroviarias de principios del siglo $\mathrm{XX}$ en el mundo, con las correspondientes de carreteras a principios del siglo XXI. La red de ferrocarriles a principios del XX "tan sólo" alcanzaba a EEUU, Europa, India, Japón, Argentina, México y poco más. Mientras que la red de carreteras a principios del siglo XXI abarca ya a todo el planeta, en general con una gran capilaridad y densidad, aunque la red de gran capacidad (autopistas y autovías) esté ubicada principalmente en los espacios centrales; y "tan sólo" también podemos decir que no hay carreteras, allí donde apenas hay población y el entorno hace muy difícil su trazado: el Amazonas, Groenlandia, el Ártico, la Antártida, y los desiertos del Sahara y Gobi. Pero igualmente hay otras redes que acompañan e incentivan esta expansión de lo Urbano, aunque a bastante distancia si las comparamos con la red de carreteras: redes de agua, eléctricas, energéticas, de telecomunicaciones y fibra óptica. Aquí, una vez más, nos volvemos a encontrar muy distintas densidades de redes entre los territorios centrales y periféricos, pues éstas interconectan sobre todo los principales nodos metropolitanos; pero como nos recuerda también Barreda, las distintas redes están convergiendo entre sí, así como los emporios empresariales que cada vez más las controlan.

El Estado en este periodo se está replegando en su papel ejecutor y gestor de estas infraestructuras, dejando el protagonismo y los beneficios al capital privado (muchas de estas infraestructuras son de peaje), pero eso sí, aportándole garantías de salvamento por si vienen mal dadas (a través de partenariados público-privados). Hay (o había hasta hace nada) mucho capital dinero en el mundo dispuesto a participar en la construcción de estas infraestructuras si se le ofrecen condiciones adecuadas (principalmente fondos de pensiones y de inversión), y además los Estados aportan también sus granos (o "granazos") de arena, aparte de que la bancos de "Desarrollo" (BM, BEI, BID, BERD, BAD, BAfD, etc.) contribuyen con abundantes créditos para que no pare la máquina de la construcción y el crecimiento. Muchas de las grandes infraestructuras ejecutadas 0 en proyecto en este periodo tienen una dimensión supraestatal, pues responden a la lógica y a las demandas de los nuevos mercados regionales planetarios y asimismo a la profundización de la 
dinámica del mercado mundial ${ }^{4}$.

Mención especial merece la creación e impacto de grandes infraestructuras de captación de agua, tanto para garantizar el suministro del líquido elemento a los espacios urbano-metropolitanos, o a las grandes actuaciones del agrobusiness, como para abastecer de energía eléctrica las conurbaciones y nuevos desarrollos industriales. Estos megaproyectos se han intensificado en este periodo especialmente en los espacios periféricos, aunque algunos de ellos ya fueron iniciados $\mathrm{y}$ ejecutados en la etapa anterior, adquiriendo una enorme repercusión por su fuerte impacto social y territorial (p.e., la presa de Asuán, en Egipto). En estos últimos treinta años la construcción de grandes presas se ha disparado en el mundo, generando una importante polémica global y considerables resistencias y luchas por parte de las poblaciones afectadas. Ese debate ha tenido una importante trascendencia, como en los casos de Narmada en India, o de la famosa presa de Las Tres Gargantas en el río Yang-Tse, en China, como consecuencia del importante volumen de población perjudicada, aparte de por el impacto sobre los sistemas fluviales afectados. Pero esos

4 En el caso de la UE destaca la construcción del túnel bajo el Canal de la Mancha, o el llamado Scanlink (gran conexión entre Dinamarca y Suecia), y las nuevas penetraciones en los Alpes y en los Pirineos, así como los más de 10.000 km de nuevas autopistas y autovías de las Redes Transeuropeas de Transporte, cifra que se contemplaba en el Tratado de Maastricht (1993) y que ha sido sustancialmente ampliada para garantizar la interconexión de la antigua UE a 15 con los 10 nuevos socios comunitarios. Redes que no solo son de transporte, sino también de energía y telecomunicaciones. Lo mismo podemos decir de las interconexiones en el TLC (Tratado de Libre Comercio), entre EEUU, Canadá y México. En el caso de América Latina, tanto el llamado IIRSA (Iniciativa para la Integración de la Infraestructura Regional Suramericana) como el Plan Puebla Panamá son hijos de estas dinámicas, con el fin de hacer posible el trasiego de agua, petróleo, gas, recursos mineros, agrícolas y forestales de América Latina, internamente y sobre todo hacia el mercado mundial. De ahí también el nuevo y costosísimo Canal de Panamá II que está en trance de construcción; el primero fue inaugurado en 1914. Pero también hay una guerra de corredores de infraestructuras en torno a la Ruta de la Seda, para la interconexión de Europa con Asia Central y Oriente Medio, con fuertes implicaciones geopolíticas. $Y$ en el Sur y Sudeste asiático las cifras son asimismo de vértigo, por no mencionar el esfuerzo inversor en infraestructuras verdaderamente hercúleo que se está acometiendo en China, que tiene asimismo una dimensión cuasicontinental. casos son tan solo la punta de un enorme iceberg. En la megapresa de Las Tres Gargantas, la mayor del mundo, las cifras son de vértigo, pues su construcción ha implicado la desaparición de casi 20 ciudades y más de 300 pueblos, lo que ha supuesto la reubicación, en un primer momento, de unos dos millones de personas. Además, estos megaproyectos no sólo han provocado importantes impactos sociales en el mundo, con decenas de millones de desplazados que han pasado a nutrir las barriadas de miseria de las Megaciudades periféricas, sino que han ocasionado igualmente importantes impactos ecológicos. En el caso de la presa de las Tres Gargantas su construcción ha generado un verdadero desastre ambiental, activando fortísimos derrumbes debido a la topografía de la zona, que han hecho necesario desplazar a otros 4 millones de personas más (WRR, 2007; EL PAÍS, 15-10-07).

Pero quizás lo más sangrante de la construcción de grandes presas sea que su vida útil es bastante perecedera. La vida útil de esas represas se sitúa en torno a los 50 ó 60 años, entre otras razones por el aterramiento que supone el almacenamiento en ellas de los sedimentos fluviales. Lo cual va a suponer que se deba desmantelar una muy gran parte de las hidroeléctricas existentes, al ser muy costoso recuperar la normalidad de su funcionamiento (Barreda, 2007). Eso por no mencionar los problemas de eutrofización que llevan aparejados muchas de ellas, y que encarecen enormemente el tratamiento hídrico para el consumo humano. Sin embargo, los problemas con la gestión del agua para abastecer las necesidades del nuevo modelo territorial no quedan circunscritos a los generados por la captación, sino que se está produciendo en muchos casos un progresivo agotamiento de los acuíferos subterráneos, cuando esta es la fuente de abastecimiento de las conurbaciones, o de la agricultura industrializada. Uno de los casos más relevantes es el progresivo 
agotamiento de los acuíferos de la gran llanura del Norte de China, donde habitan más de 200 millones de personas en grandes metrópolis, entre las que se encuentra Pekín. El abastecimiento de todo este inmenso espacio está en serio peligro, y se están contemplando nuevos y costosos trasvases gigantescos Sur-Norte desde la ya castigada cuenca del Yang Tse (Wong, 2007). Los fuegos de artificio que han iluminado el gran estadio de El Nido de Pekín, asombrando al mundo con ocasión de los recientes Juegos Olímpicos, serán incapaces de permanecer en el tiempo y ocultar el enorme desastre ambiental que se avecina.

Sin embargo, la construcción de todos estos megaproyectos tiene por supuesto una razón de ser, pues aparte de acompañar e incentivar el tsunami urbanizador mundial, hay muy importantes actores globales que se benefician de su ejecución. Desde las grandes compañías de construcción de los espacios centrales, que se habían desarrollado y consolidado en el periodo anterior, y que refuerzan su escala y proyección global ahora. Hasta los grandes grupos financieros que financian y apoyan estos megaproyectos. Pasando por grandes firmas internacionales de ingeniería y tecnológicas que asesoran en su construcción. Una construcción que supone una fuerte demanda adicional de la producción de creciente complejidad tecnológica, para esta expansión de lo Urbano cada vez más artificializada y que refuerza hasta extremos inconcebibles la Megamáquina global. Igualmente, en estos megaproyectos su presupuesto de ejecución se suele multiplicar sustancialmente a lo largo de su construcción, lo que beneficia a los actores ya señalados y endeuda aún más a los Estados respectivos, y en definitiva a sus ciudadanos, que son los que cargan con el peso de esa deuda (Naredo, 2008).

\section{La metrópoli del siglo XXI, entre la Ciudad Global y la Megaciudad Miseria}

En los últimos 30 años, el renovado e intenso crecimiento de la lengua de lava metropolitana a escala mundial ha alumbrado como ya hemos recalcado dos nuevas formas de conurbación: la Ciudad Global en los espacios centrales, y la Megaciudad Miseria en los periféricos, si bien hay un abanico de continuidad entre unas y otras, sobre todo en los llamados "espacios emergentes". Estamos en un capitalismo global crecientemente multipolar con nuevos Estados "emergentes", que empiezan a disputar la hegemonía a los centros occidentales de la Economía Mundo, mientras que determinados territorios (p.e. gran parte de África) profundizan su situación periférica, y es por eso por lo que la jerarquía del sistema mundial de metrópolis está en lenta pero constante redefinición. Ciudades Globales y Megaciudades Miseria, y en ocasiones su mezcla, son pues las formas espaciales metropolitanas más recientes del nuevo capitalismo global, que reflejan sobre el territorio la jerarquización variable de las relaciones de poder, las dinámicas de integración y exclusión que operan en el mercado mundial, así como las consecuencias de la creciente transnacionalización y financiarización de la Economía Mundo. En definitiva, esas realidades son la actual expresión de la concentración de riqueza y acumulación del capital en el espacio, y de su correlato de condensación de la pobreza y miseria extremas, al tiempo que las nuevas conurbaciones actúan de receptáculo de las "clases medias" urbanas que hacen viable este modelo, amplias en los países centrales y bastante limitadas en los periféricos.

En este periodo también la forma metrópoli alcanza una renovada centralidad y protagonismo, y hasta en muchos casos independencia en relación con la estructura estatal de la que forma parte, al tiempo que amplia su dimensión espa- 
cial, convirtiéndose en verdaderas regiones metropolitanas. En la redoblada competitividad que introduce el nuevo capitalismo global, ya no sólo compiten entre sí los Estados en el mercado mundial, sino también los territorios y las regiones metropolitanas, con el fin de atraer los flujos cada vez más variables y volátiles de la inversión internacional. Los territorios estatales dejan de ser espacios "unitarios", al quedar abiertas sus economías a las lógicas del mercado mundial, y sus principales regiones metropolitanas son las que se articulan con mayor intensidad con los flujos productivos y financieros globales, y se ven asimismo condicionados por ellos. Es por eso por lo que las estructuras de poder estatal y local promueven especialmente la imagen marca de las nuevas metrópolis, dedicando importantes recursos económicos de cara a su mejor venta en el exterior.

Pero es más, la nueva metrópoli de los espacios centrales se transforma en un mecanismo perfecto de la creciente financiarización de la "ciudad", pues la producción de vivienda se orienta cada vez más hacia la lógica de mercado y bancaria (impulso de la vivienda en propiedad, retirada del Estado de la construcción de vivienda social, desregulación del mercado de alquileres, importante expansión del mercado hipotecario), al tiempo que la producción y gestión del espacio urbano se convierte en un importante ámbito de acumulación de capital (intensificación de la compra-venta del patrimonio inmobiliario y paulatina titulización del mismo, que empieza a operar en los mercados financieros: aparición de los REIT ${ }^{5}$ ). El espacio urbano se mercantiliza pues cada vez más y se convierte en un estupendo bien de inversión, es decir, en un depósito de valor que se revalori-

5 Real State Investment Trust, una especie de fondos de inversión en el sector inmobiliario, de baja fiscalidad, que empieza a desarrollarse en EEUU en los setenta, intensificándose en los ochenta y noventa, y que a partir de los noventa saltaría a Europa occidental y a otros países de la OCDE. za constantemente al alza. Los precios de los activos inmobiliarios de las Ciudades Globales experimentan en este periodo un alza importante, y la nueva metrópoli se convierte en uno de los espacios preferidos donde se embalsa la riqueza monetaria mundial. Los precios en los principales centros metropolitanos (Nueva York, Londres, Tokio, París, etc.) adquieren niveles de infarto.

Por otra parte, la metrópoli de los países centrales se desparrama aún más sobre el territorio, y sufre una importante metamorfosis en estos últimos 30 años, convirtiéndose las más importantes de ellas en verdaderas Ciudades Globales (Nueva York, Londres, Tokio, París, Chicago, etc.)(Sassen, 1991). Es decir, en los lugares centrales desde donde se dirige la nueva Economía Mundo. Es en ellas donde se ubica el grueso de las sedes de las grandes empresas transnacionales y los principales centros financieros globales. Los dos grandes actores del nuevo capitalismo global. $Y$ el papel mundial de estas Ciudades Globales está también fuertemente marcado por la Historia (Londres y Nueva York, como centros financieros globales y sedes principales del mercado global del petróleo; Chicago, centro del mercado mundial del grano; etc.). En paralelo, en este periodo el peso industrial de las metrópolis centrales se reduce sustancialmente, pues la deslocalización productiva hace que la nueva Fábrica Global pase a ubicarse principalmente en determinados espacios periféricos, al tiempo que se centralizan los procesos de toma de decisiones y de gestión de la "globalización" (actividades financieras, servicios especializados, publicidad, ingeniería, $\mathrm{I}+\mathrm{D}+\mathrm{i}$, etc.) en las Ciudades Globales. Hecho que es posibilitado por las nuevas tecnologías de la información y comunicación, y por la progresiva desmaterialización del dinero y su conversión en pura información. De esta forma, asistimos a un importante proceso de reestructuración de los espacios centrales de las metrópolis 
centrales (valga la redundancia), donde pasan a ubicarse las funciones de comando y financieras de la Economía Global, que actúan asimismo en estrecha relación con los Paraísos Fiscales. Un fenómeno que adquiere un desarrollo e importancia trascendental en este periodo.

Es por ello que va a ser necesario desplazar antiguas funciones y sectores sociales que habitaban en los centros metropolitanos, al tiempo que se ejecutan determinados megaproyectos de transformación de los mismos para acoger a las nuevas funciones globales. Si bien en los últimos tiempos asistimos a una considerable deslocalización de parte de estas funciones globales (en general sus componentes más subsidiarios), no solo hacia las periferias metropolitanas sino en ocasiones hasta a los propios países periféricos 0 semiperiféricos. La reducción de costes juega a favor de esta dinámica. En este sentido, el caso de India es paradigmático. Así, si China se ha convertido en la Fábrica del Mundo, India se está transformando en su Oficina, pues no en vano los trabajadores indios dominan el inglés. Pero también la creciente terciarización de las Ciudades Globales viene determinada por el fuerte desarrollo de la producción cultural y mediática de estas metrópolis, así como por su función de importantes centros universitarios y de investigación, y por su papel en ascenso como centros de Ferias, Congresos y Exposiciones.

Igualmente, en las remozadas metrópolis de los Estados centrales van a irrumpir con especial fuerza nuevas formas de distribución comercial: los grandes centros comerciales (el modelo "WalMart-Carrefour"), las nuevas catedrales del consumo, que se van a ubicar especialmente en las periferias metropolitanas en este periodo. Estas nuevas formas comerciales van a estar muy ligadas al uso cada día más amplio del vehículo privado, van a ser el reflejo territorial de las nuevas pautas de consumo ligadas a la nueva Fábrica
Global y al predominio mundial del Agrobusiness, van a actuar como un elemento importante del crecimiento en mancha de aceite de los espacios metropolitanos y se van a convertir en actores claves del nuevo capitalismo global. Recientemente Wal-Mart acaba de desplazar a General Motors como principal empresa a escala mundial. Esta dinámica ya se había iniciado en EEUU antes de las crisis de los 70 , pero no salta abiertamente a Europa occidental y a otros Estados centrales hasta después de los 80 . Al igual que el crecimiento de baja densidad residencial (viviendas unifamiliares, chalés adosados) característico de las periferias metropolitanas estadounidenses, que se difunde asimismo ampliamente en otras metrópolis centrales fuera de EEUU durante esta etapa. Pero también se ubican en las periferias ampliadas de dichas metrópolis centrales los nuevos espacios de ocio mercantilizado, entre los que destacan especialmente los llamados parques temáticos, dominados por los gigantes de la industria del entretenimiento (Disney, Warner Brothers, etc.), que pasan a ser un componente habitual de la nueva metrópoli postmoderna. $E$ igualmente, la antigua Fábrica Fordista se reestructura y estalla sobre el territorio (aquella que no se deslocaliza hacia la Periferia), generándose la denominada Fábrica Difusa. De esta forma, permanece en la nueva Fábrica Postfordista la actividad productiva de mayor componente tecnológico (la cadena de montaje computerizada y robotizada), mientras que una pléyade de actividades industriales auxiliares se localizan de forma crecientemente dispersa en los bordes de las nuevas regiones metropolitanas. $Y$ al mismo tiempo, proliferan nuevos tejidos de industria High-Tech (Parques Tecnológicos), que se ubican en nuevas extensiones metropolitanas a lo largo de ejes de transporte de alta capacidad (Silicon Valley y similares).

Todo ello supone un renovado estallido de la me- 
trópoli postmoderna de los espacios centrales sobre el territorio, especialmente intenso en las Ciudades Globales, que hace que la onda expansiva de la „bomba lenta" que comentábamos anteriormente se vea especialmente intensificada en este último periodo. Indudablemente, este renovado estallido no hubiera sido viable sin la garantía de un flujo petrolífero barato y en ascenso, y sin una expansión sin precedentes del consumo de energía eléctrica, una gran parte de él asimismo de origen fósil. Pero también las nuevas tecnologías de la telecomunicación y la información han contribuido a este nuevo desparramo sobre el territorio de los tejidos urbano-metropolitanos, ya que han posibilitado una aún mayor desarticulación, reestructuración, descentralización y especialización de las actividades y del habitar sobre el territorio, acentuando la segregación social. Además, las nuevas tecnologías lejos de reducir las necesidades de transporte, como se dijo en un primer momento, no han hecho sino potenciar todavía más la movilidad motorizada. En definitiva, las telecomunicaciones han supuesto una mezcla explosiva ideal para potenciar la onda expansiva de las metrópolis y el transporte motorizado (Sanz, 1997), principalmente en las Ciudades Globales centrales.

Pero también se están desarrollando Ciudades Globales de segundo orden en la semiperiferia, en los nuevos espacios "emergentes" del capitalismo global, algunas de indudable trascendencia económico-financiera regional, siendo a su vez muchas de ellas auténticas Megaciudades Miseria. Los casos de Pekín, México DF, Sao Paulo, Buenos Aires, Johannesburgo, Delhi, Mumbai o Yakarta, entre muchos otros, podríamos incluirlos en esta categoría de Ciudades Globales "emergentes". Sassen (2006) nos viene a decir que existen unas 40 metrópolis mundiales que se podrían considerar Ciudades Globales. Unas de primer orden, las centrales, y otras de segundo orden, las semiperiféricas o "emergentes". Pero todas ellas actúan íntimamente interrelacionadas a través de un espacio de flujos materiales e inmateriales, que configuran redes jerarquizadas en proceso constante de cambio y redefinición, desde las cuales se impulsa y gestiona la Economía Mundo. Pero como decimos, muchas de estas Ciudades Globales de segundo orden son a su vez Megaciudades Miseria donde se concentran gran parte de los 1000 millones de personas ya mencionados que habitan en condiciones de extrema miseria en suburbios gigantescos (de favelas, ranchitos, villas miseria, chabolas, etc.; distintas denominaciones para un mismo fenómeno). $Y$ en el escalón más bajo de la jerarquía mundial del sistema de grandes metrópolis mundiales lo que predomina es la Megaciudad Miseria con pocas y muy subsidiarias funciones globales, que actúan de engarce de sus territorios con el mercado mundial, y a su vez son resultado del impacto de éste sobre los mismos. Es el caso principalmente de las grandes metrópolis subsaharianas: Lagos, Nairobi, etc.; de algunas asiáticas: Manila, Calcuta, Hanoi, etc.; o de ciertas metrópolis latinoamericanas de segundo nivel: Lima, La Paz, Quito, etc.

Uno de los rasgos más característicos de la Megaciudades Miseria, en especial en sus escalones más bajos, es su fortísima dualización, y la existencia dentro de la misma metrópoli de dos mundos absolutamente diferentes. Aquél conectado con la Economía Mundo, y aquél otro absolutamente marginado de la misma. Aquél ligado a la economía formal y que participa en parte de los mismos "avances" de las metrópolis centrales: Grandes Centros Comerciales, transporte motorizado, vivienda producida industrialmente y urbanizada, de aquél otro en que estos "adelantos" son inalcanzables. Es más, la venta ambulante en estas conurbaciones es el contrapunto de los "Shopping" superprotegidos, en los que compran 
las clases medias. Esta venta ambulante se ubica a lo largo de las vías de transporte, en los centros de intercambio y hasta en el metro allí donde existe, y en muchos casos es un negocio controlado también por mafias. La dualización de las Megaciudades Miseria es pues salvaje. En Nairobi, un prototipo de Megaciudad Miseria, las masas de desheredados caminan sin fin por los bordes de las autovías, pues no tienen ni siquiera la posibilidad de acceder a un transporte colectivo altamente degradado y hacinado de camionetas, que sólo pueden utilizar (debido al precio) los "privilegiados" empleados que trabajan en los escalones más bajos de la economía formal.

Es preciso resaltar un apunte postrero sobre las nuevas formas constructivas de la metrópoli postmoderna. En ella, el mundo de la arquitectura lleva a sus límites la lógica postmoderna, especialmente en sus piezas principales que se conectan a la Economía Global, y cumplen un papel significado en esa interrelación. $O$ bien en los lugares privilegiados habitacionales y de disfrute de la nueva clase de hiperricos, o de los gestores globales. En ellos la Diferencia parece por fin haber derrotado a la autoritaria homogeneidad Moderna. Los nuevos edificios emblemáticos de exuberante y fascinante belleza, artefactos rebosantes de significados en el gran supermercado de las formas, y que llevan muchos de ellos el sello personalizado de los Arquitectos Estrella, se distancian de forma nítida y contundente del resto de la metrópoli. Además, se reproduce por doquier el síndrome de la Torre Eiffel, o el efecto Guggenheim, y todas las metrópolis globales quieren participar de esta Arquitectura Espectáculo. Unas lo pueden hacer con profusión, exhibiendo cada vez más edificios y construcciones Estrella, en un derroche de Arquitectura y Poder, y otras en cambio se ven obligadas a dosificar estas manifestaciones. Menos ejemplares, pero igual de potentes y dispendiosos. La Sociedad del
Espectáculo también se manifiesta en el espacio metropolitano como la "Ciudad del Espectáculo". Un decorado inmenso detrás del cual a duras penas se logra ocultar el drama complejo de lo social y por supuesto el derroche energético de la metrópoli postmoderna (Verdaguer, 1998). El ataque del 11-S, y el derrumbe consiguiente de las Torres Gemelas, pareció que iba a ser un freno a la construcción de grandes rascacielos espectaculares. Pero lejos de ello, la edificación de gran altura (sin límite aparente) no ha hecho sino progresar sin freno en los primeros años del nuevo milenio, como resultado del tsunami urbanizador impulsado por la burbuja inmobiliaria mundial; eso sí, hasta su reciente estallido como consecuencia de la crisis financiera y energética.

Finalmente, en este periodo también se consolida una nueva forma espacial: la Megalópolis, es decir, un conjunto interrelacionado de metrópolis sobre el territorio, cuyos crecimientos se llegan a tocar y hasta solapar. Este fenómeno es sobre todo privativo de los espacios centrales, pero también está manifestándose ya en algunos de los principales espacios periféricos "emergentes", especialmente en el caso de China. Las primeras Megalópolis ya empezaron a cuajar en EEUU antes de las crisis de los 70 , en el corredor entre Boston y Washington, y en California entre Los Ángeles y San Diego, y es entonces cuando Gottman (1957) acuña esta denominación (Mumford, 1963). Pero a Europa occidental y Japón no saltaría este proceso hasta estos últimos 30 años, pues sus crecimientos metropolitanos eran más "contenidos" y "limitados" espacialmente. Pero en las últimas décadas se está produciendo un fenómeno similar en el corazón de la UE, en el llamado "Pentágono": el área formada por Londres, París, Hamburgo, Munich y Milán, donde se concentra el grueso de la población y la riqueza, así como los principales centros financieros, políticos y decisionales de la Unión. $Y$ entre ellos por su- 
puesto Bruselas, el "Washington" de la Unión. El "Pentágono" se ha visto reforzado por el Mercado Único, la moneda única y la expansión de la UE (Fdez Durán, 2006). Lo mismo podríamos decir del caso de Japón, donde encontramos una dinámica similar entre Tokio y Osaka. Por último, en China en su fachada de grandes metrópolis del Pacífico se está materializando ya un proceso parecido. Hacia esas metrópolis se han desplazado ya unos 300 millones de personas desde el interior en los últimos 30 años, y las previsiones son que acudan grosso modo otros 300 millones en las dos próximas décadas (Arrighi, 2007). Sin embargo, como veremos más adelante, todo parece indicar que dichas previsiones van a ser muy difícil que se cumplan. Aun así, la megalópolis china del Pacífico ya se está convirtiendo en una tremenda realidad.

El desarrollo metropolitano chino es sencillamente espectacular. China ha evitado el chabolismo horizontal de las Megaciudades periféricas o semiperiféricas, pero ha promovido un asombroso chabolismo vertical, con edificios residenciales en altura que no se ven en ninguna metrópoli del mundo (ni siquiera en Sao Paulo, donde abundan junto con el chabolismo horizontal). La edificación en altura domina la construcción metropolitana en China, con edificios espectaculares en sus metrópolis más emblemáticas (en especial en Shangai y Pekín). $Y$ el nuevo e intensísimo crecimiento metropolitano ha logrado arrasar con lo que quedaba de la ciudad tradicional. El diseño de ésta que se hacía históricamente teniendo en cuenta el Feng Shui, la harmonía entre el ser humano y la naturaleza, ha pasado a estar presidido por la lógica salvaje del mercado y la modernización a ultranza. Tan solo unas pequeñas manchas de los llamados Hutong, los barrios de edificaciones de una altura típicos de la ciudad tradicional china, son hoy en día el testigo mudo en Pekín, en torno a la Ciudad Prohibida, de una historia urba- na que ha sido arrasada en aras del "Desarrollo" sin límites. Y las metrópolis chinas gozan del privilegio de ser las más contaminadas del mundo.

Por último, decir que en todo este periodo el consumo de electricidad en las distintas metrópolis mundiales verdaderamente se desboca, debido a las nuevas estructuras productivas que acoge, a su creciente dispersión territorial y a las nuevas tipologías residenciales, comerciales y terciarias, a la intensificación de la iluminación metropolitana, a la expansión de los sistemas de transporte electrificados (metro y tren) y de las redes de distribución de agua (impulsadas también por energía eléctrica), así como al ampliado equipamiento electrónico de los hogares y a la intensidad de su uso (entre otras cuestiones debido a Internet y a las nuevas tecnologías de la información y comunicación). Indudablemente, la intensidad del uso de la energía eléctrica es especialmente acusada en las metrópolis centrales, y muy en concreto en las Ciudades Globales.

\section{La enfermedad del transporte motorizado se agrava patológicamente y se globaliza}

A nadie se le escapa que el nuevo modelo productivo y territorial del capitalismo global que se ha impuesto a escala mundial en las últimas tres décadas implica un auge sin precedentes de la movilidad motorizada a todos los niveles: por tierra, mar y aire; un salto verdaderamente cualitativo en relación con la etapa previa, ya de por sí altamente basada en el transporte motorizado. Pero es más, la valoración social de las ansias de la movilidad motorizada privada, sobre todo por carretera y aérea, en automóvil y en avión, adquiere en estos años como veremos una trascendencia absolutamente inusitada, afectando ya prácticamente a todas las culturas y a todo el planeta. La enfermedad del transporte se ha pues globalizado, y en algunos territorios se ha hecho verdaderamente patológica, habiendo traspasado 
fronteras que parecen ya de no retorno. Sin embargo no hay nada que pueda crecer sin fin en un planeta finito, ni nada humano que sea eterno.

Y la explosión de la movilidad motorizada que ha tenido lugar en este último periodo auspiciada por el petróleo barato, será la primera víctima propiciatoria cuando se recrudezca la crisis energética mundial, como ya está sucediendo. Pero analicemos algo más detenidamente la dimensión del salto cualitativo acontecido en el transporte motorizado durante este último periodo, en el que hemos entrado de lleno en la era (efímera) de la hipermovilidad, en la que las distancias diarias que recorre una parte importante de la población mundial y sobre todo las mercancías se han disparado.

El transporte motorizado ha estado creciendo en todo este periodo a un ritmo sustancialmente superior al ritmo del crecimiento económico, habiendo sido éste muy importante (exponencial) a lo largo de estos casi treinta años. En un informe encargado por la Comisión Europea a principios de los 90 se alertaba de que el transporte motorizado estaba creciendo a un ritmo que casi duplicaba el crecimiento económico; y esto lo podemos extender fácilmente a escala planetaria pues el comercio internacional ha crecido a un ritmo muy superior al crecimiento de la economía mundial, como resultado de la profundización de los procesos de globalización. Lo mismo podemos decir de los flujos comerciales en los mercados regionales planetarios, que han crecido también a un ritmo muy superior al crecimiento de las economías nacionales, como resultado de las transformaciones acontecidas en la división internacional del trabajo y del progresivo predominio de la producción a gran escala (Fdez Durán, 2000; GT2000+, 1990). Por otro lado, la expansión espacial de la lengua de lava metropolitana (auspiciada también por las nuevas tecnologías) no ha hecho sino crear continuamente lejanía, por lo que las necesidades de desplazamiento cotidiano han acentuado la movilidad motorizada obligada. Pero también ha experimentado un verdadero estallido la movilidad motorizada libremente deseada, debido al fuerte auge de la tasa de motorización mundial. Y finalmente, la cada vez mayor desigualdad social, y la concentración de riqueza en una parte pequeña pero considerable de la población mundial, no ha hecho sino intensificar la movilidad de larga distancia (turismo continental e intercontinental), ante el atractivo del conocimiento de lo exótico y lejano.

El más lejos y más deprisa se han consolidado pues como valores incuestionables, y en elementos esenciales de la dinámica aceleradora de las sociedades actuales.

En este periodo el número de coches a nivel internacional se duplica, saltando de unos $400 \mathrm{mi}-$ llones a 800 millones (Estevan, 2008; Swedetrack, 2008). El grueso de este crecimiento hasta principios de este siglo ha sido en los países de la OCDE (el $90 \%$ aproximadamente), en donde paulatinamente las tasas de motorización han ido acortando distancias respecto a las de EEUU, aunque éstas no han parado de aumentar, alcanzando ya casi los 800 vehículos por 1000 habitantes (Fdez Durán, 2000 y 2008; Heinberg, 2006). Pero en los últimos tiempos el crecimiento de la motorización está siendo especialmente intenso en los espacios "emergentes", y muy en concreto en China, donde en pocos años prácticamente han desaparecido las bicicletas de sus principales metrópolis. China además se ha convertido ya en el primer productor mundial de automóviles. Es de resaltar la fuerte atracción que el automóvil ha tenido en las poblaciones no occidentales, tanto del Este como del Sur. El icono del automóvil occidental de elevadas prestaciones y bellas formas ha sido sin ninguna duda la mercancía más preciada en el tránsito acelerado de las sociedades "comunistas" hacia su integración en el capi- 
talismo global, o en el de las periféricas hacia su mayor modernización. El que esto escribe pudo apreciar en directo cómo en los días posteriores a la caída del Muro de Berlín, las riadas de población del Este que acudían a Berlín occidental, los lugares que más visitaban, agolpándose extasiadas, eran los concesionarios de BMW, Mercedes o Audi, en donde familias enteras se subían a los vehículos que allí se exhibían para poder disfrutarlos, aunque sólo fuera de esa forma.

Detrás habían dejado un paisaje de desvencijados Travis (el coche popular de la antigua RDA), con motores de dos tiempos y altamente contaminantes, incapaces de competir con la exuberancia, potencia y glamour de la tecnología automovilista occidental.

En estos casi 30 años, por tanto, el automóvil se ha transformado en el emblema por excelencia de la Modernidad a escala mundial, y en el verdadero símbolo civilizatorio de la sociedad industrial avanzada. Es más, en las sociedades centrales el paso a la edad adulta está marcado ya por el acceso al carnet de conducir y al uso del automóvil ("conduzco, luego existo"), y el coche se ha convertido en el instrumento ideal para la penetración de los valores dominantes y la domesticación del conjunto de la sociedad. No solo porque la posesión de un vehículo ha sido una de las vías para doblegar las resistencias y las culturas obreras, ya que el endeudamiento que su acceso comporta implica que las luchas remiten ante el temor de no poder pagar el crédito. Sino también porque la compra de un vehículo de alta potencia se convierte en la vía ideal para el desclasamiento rápido de los sectores trabajadores, aunque luego les resulte difícil llegar a fin de mes. Cuando uno o una va conduciendo un BMW se convierte en objeto de envidia de los que le contemplan, y nadie sabe de dónde procede, dónde habita, en qué trabaja, ni qué esfuerzo económico incurre para disfrutarlo. Igualmente, cuando un inmigrante mexicano en EEUU, o un magrebí en la UE, va a pasar las vacaciones a su país de origen en su flamante automóvil despierta la admiración de sus congéneres, pues en principio parece una muestra palpable del éxito alcanzado. Pero nadie sabe las penurias que tiene que hacer frente para poder desplegar esa capacidad de seducción, pues para pagarlo seguramente se ha tenido que endeudar hasta las cejas. $Y$ muy probablemente ese mismo inmigrante sea reacio a volver a su país para unos días de descanso, si no ha sido todavía capaz de acceder a un automóvil. De esta forma, no tendrá que mostrarse como un "perdedor" ante los vecinos que le vieron partir.

La veneración del automóvil se ha pues universalizado, convirtiéndose en una auténtica religión, y el coche se ha mostrado como el virus más eficaz para facilitar que la Modernidad occidental colonice y doblegue otras culturas, incluso aquellas más reacias a sus postulados. Es más, el transporte por carretera se ha convertido en uno de los vehículos principales de homegeneización planetaria (señales de tráfico y por carretera, códigos de circulación, estaciones de servicio, talleres de reparación, etc.). El automóvil ha transformado absolutamente el paisaje de los territorios más modernizados, y hasta de aquellos en trance de modernización, pues es capaz de llegar ya a todos los lugares del planeta. Esa es la meta que nos vende la publicidad en relación con los $4 \times 4$, en el mundo onírico de deseos y sensaciones que nos promete. Y hasta la Formula 1, un deporte de elite que empezó de forma balbuciente en 1950, ha acabado penetrando nuestra vida cotidiana a través de las pantallas en todo el mundo, actuando como un atractivo cóctel de competitividad, velocidad, escaparate de la alta tecnología, espectáculo, negocio y feria de las vanidades, que ha globalizado ya el circo de su representación continua prácticamente a todo el planeta. Circo 
que es seguido con avidez por centenares de millones de personas. Ya hay circuitos que lo acogen en todos los continentes y en todos los países que quieren contar algo en la Economía Mundo, aunque sea a costa de derrochar recursos públicos en esta bobería de gran capacidad de seducción.

El elixir de la velocidad, una especie de éxtasis que la revolución tecnológica ha brindado al ser humano, se intenta vender en diferentes dosis a "toda" la Humanidad. Recientemente acaban de salir al mercado automóviles a 2000 euros, producidos por la empresa india Tata, un gigante industrial en expansión (que acaba de comprar las empresas Jaguar y Land Rover), para ayudar a extender la tasa de motorización en India, y en el resto de países periféricos, haciendo accesible este preciado bien a franjas aún más amplias de la población mundial; aunque éstas acceden también a través de la compra de los vehículos de tercera o cuarta mano que se "reciclan" de las sociedades centrales a las periféricas y dentro de ellas. El fuerte avejentamiento es una de las características prominentes del parque móvil en los países periféricos, allí los Estados no se pueden permitir planes "Renove". $Y$ quien sabe si no intentarán vender las bagatelas de los coches a 2000 euros en los países centrales, en esta época de crisis. Los planes son por tanto volver a duplicar el parque mundial de vehículos en los próximos 20 ó 30 años, si es que las entrañas de la Tierra y otros impedimentos lo permiten; en definitiva, el llamado pico del petróleo y el fin de la era de la energía barata, así como otras resistencias sociales y la crisis global en marcha.

Pero el transporte por carretera de pasajeros es mucho más que el automóvil, aunque el vehículo privado sea su expresión más simbólica y universal. En este periodo otros medios que es preciso encuadrar en ese capítulo han experimentado también un salto espectacular a escala mundial.
Desde las motocicletas de alta, media y baja cilindrada, para atender todas las demandas y todos los públicos posibles, y que también tienen su propio circo mediático de seguidores (Moto GP, p.e.), hasta la proliferación inusitada de toda clase de camionetas y autobuses. El parque de esos vehículos se ha más que duplicado en el periodo que analizamos, habiendo sido particularmente intenso su crecimiento en los espacios periféricos (Swedetrack, 2008). Este hecho, junto con la gran difusión de vehículos y motos "Todo Terreno", ha permitido ampliar la movilidad motorizada en los territorios de difícil acceso y hasta en los lugares más recónditos del planeta. Igualmente, la aparición de nuevos artefactos que potencian una mayor irrupción de la movilidad motorizada como los Quad, y hasta las motos acuáticas, provoca que sea muy difícil ya encontrar espacios a salvo del ruido del motor de explosión (o del motor diesel), y que el radio de acción del Homo Motorizadus llegue a prolongarse más allá de los bordes costeros. Y más al interior de los mares, una subespecie del Homo Motorizadus, aquellos especímenes privilegiados que se han hecho en esta etapa con la posesión de yates, amplían como nunca en la historia el radio de acción humano puramente de ocio sobre mares y océanos, sobre todo en los espacios marítimos más próximos a los espacios centrales (el Mediterráneo, el Caribe, etc.), utilizando para ello un reguero de puertos deportivos de nueva creación.

Sin embargo, como decíamos anteriormente, el crecimiento más intenso del transporte se ha experimentado en relación con el movimiento de mercancías. El volumen y peso mayor de mercancías transportado en el mundo es el que se trasiega en bruto, principalmente combustibles, minerales y grano, a través de transporte motorizado por mar y tierra, fundamentalmente, pero también mediante oleoductos y gasoductos. Pero en este periodo se impone a escala planetaria el 
transporte por containers para el grueso de las mercancías manufacturadas de la Fábrica Global, lo que facilita el transporte intermodal, permitiendo enlazar el transporte marítimo y terrestre.

Dicho transporte es realizado en grandes buques (de hasta 10.000 contenedores), en general entre los principales puertos del mundo (Rótterdam -la boca de la UE-, Singapur, Nueva York, Shangai, etc.), altamente automatizados, y de ahí en otros barcos de menor volumen, hacia puertos de segundo orden, o por tierra a través de redes ferroviarias y grandes camiones de larga distancia, hasta que esos containers alcanzan sus destinos finales. Pero antes, normalmente, pasan por enormes y tecnologizadas áreas logísticas, que facilitan el almacenaje, redistribución y ruptura de carga. Al cabo, esas manufacturas llegarán a sus usuarios finales, que son tanto la propia actividad productiva, para sus procesos de producción just in time, como el consumo final, cada vez más ubicado en las nuevas catedrales del consumo: los grandes centros comerciales.

Aquí, una vez más, queremos resaltar la gran cantidad de espacio que se dedica a la actividad del transporte motorizado, que es la verdadera columna vertebral material del nuevo capitalismo global. Y un indicador del cambio del peso productivo de la Fábrica Global de Occidente hacia Oriente, es el hecho de que hoy en día el tráfico portuario en el Pacífico dobla ya al de todos los puertos del Atlántico (Barreda, 2005 y 2007).

Pero otra parte cada vez más importante de esa columna vertebral es el transporte aéreo, que ha crecido en estas últimas décadas a ritmos superiores aún al crecimiento del transporte marítimo y terrestre, sobre todo en lo que al tráfico de pasajeros se refiere. La aviación comercial se ha convertido también en un potente vehículo de homogeneización planetaria (normativa aérea, tecnología aeronáutica, construcción y simbología de aeropuertos, servicio en los aviones, etc.), y en un elemento trascendental de la penetración de los valores de la Modernidad a escala mundial, en concreto la velocidad, y en la conformación de un nuevo imaginario colectivo global de los sectores sociales que lo utilizan. El transporte aéreo ha dejado de ser un transporte de elites en esta última etapa para convertirse en un elemento central de la movilidad motorizada del nuevo capitalismo global. Tanto por el cada día mayor trasiego entre las principales metrópolis que comporta el funcionamiento de una economía cada vez más mundializada, que requiere el transporte aéreo (es decir, lo más rápido posible) de su tecnoburocracia y cúpulas propietarias; pues éstas precisan de reuniones cara a cara para potenciar y engrasar la economía transnacionalizada y financiarizada, ya que las interconexiones inmateriales no son suficientes. Como por el salto sin precedentes que ha experimentado en estas décadas el turismo continental e intercontinental, alcanzando los 800 millones anuales. El turismo ha dejado de ser en estos años una actividad de ocio de las elites, para democratizarse a amplios sectores de las clases medias de los países centrales. Ello se ha visto favorecido por la importante revalorización de las divisas centrales respecto de las divisas periféricas, acentuando el efecto riqueza de las clases medias del Norte a escala global, y por el fuerte abaratamiento que experimentó el transporte aéreo en estos años auspiciado por la energía barata, la desregulación aérea, el apoyo estatal (fuertes inversiones en aeropuertos y el hecho de que el queroseno no paga impuestos) y la irrupción de las compañías Low Cost. Este sector ha facilitado también el creciente trasiego de la fuerza de trabajo inmigrante entre los espacios centrales y periféricos, y en menor medida entre los propios espacios periféricos. Por supuesto, todo este escenario está cambiando rápidamente con el recrudecimiento de la crisis energética y económica, el incremento de las tarifas aéreas y 
la crisis de las aerolíneas.

Sin embargo, el intento de ganar en rapidez y velocidad es en gran medida un intento vano, pues al final el colapso circulatorio (y hasta aéreo) es cada día más generalizado. Un colapso que ya desborda las metrópolis y que afecta a regiones enteras. El tráfico ha destruido la habitabilidad de las ciudades y ahora lo está haciendo en las regiones metropolitanas y en las grandes vías de interconexión entre ellas. Ya no sólo afecta principalmente a EEUU, como en el periodo anterior. El infarto circulatorio en la Unión Europea por ejemplo está alcanzando ya prácticamente a todo el "Pentágono", la nueva Megalópolis europea, aparte de por supuesto a todas las metrópolis y grandes áreas urbanas fuera de él. Pero lo mismo podríamos decir de los tejidos urbanometropolitanos a escala mundial. Todo lo cual implica la enorme contradicción de intentar ahorrar tiempo, para derrocharlo de forma continúa, pues en definitiva, todo intento de acortar las distancias largas, no hace sino alargar las distancias cortas, y disparar el tiempo dedicado a transportarse. En este periodo, el tiempo social dedicado al transporte en las metrópolis se eleva hasta casi a una tercera parte del tiempo humano disponible, y además, el tiempo de transporte se acaba convirtiendo en un tiempo de trabajo no remunerado. Cuantas más carreteras se construyen, más automóviles circulan por ellas y más grandes son las metrópolis, más largas son las distancias a recorrer, más congestionado está el tráfico y menos tiempo parece tener la gente (Vega, 2007; Fdez Durán, 2000). La siguiente reflexión de la novela Momo es de lo más pertinente para definir la patología globalizada del transporte: "Lo extraño era que, a pesar de todo el tiempo que ahorraba, nunca le quedaba nada para gastar, pues de alguna forma misteriosa simplemente se desvanecía" (Ende, 1994).

La expansión incontenible del transporte motori- zado, y todo lo que ello conlleva, se está convirtiendo ya en el núcleo duro de la crisis ecológica mundial. Los medios de transporte que se han potenciado más en este periodo son los más consumidores de energía y los de mayor impacto ambiental. El transporte por carretera consume grosso modo dos veces más de energía (por pas $x \mathrm{~km} y$ tn $x \mathrm{~km}$ ) que el ferrocarril convencional, que experimentó un fuerte abandono en este periodo; especialmente en grandes estados semiperiféricos donde se desarrolló de forma importante en el siglo XIX y principios del XX: Argentina y México, y donde prácticamente ha sido desmantelado en los últimos años. El fuerte crecimiento de vehículos de alta cilindrada y de $4 \times 4$, junto con la expansión de los kms recorridos por vehículo, han contrarrestado totalmente cualquier efecto positivo que haya podido tener el incremento en la eficiencia energética de los vehículos ("efecto rebote"); los $4 \times 4$, p.e., consumen dos veces más de energía que el avión. Por otro lado, el transporte aéreo consume tres veces más energía que el ferrocarril convencional. $Y$ además, se ha propiciado la expansión del ferrocarril de alta velocidad que es altamente consumidor de energía; en el colmo de las paradojas asistimos ahora a la construcción de una carísima conexión en alta velocidad Buenos Aires-Rosario, cuando se ha desmantelado la extensa red ferroviaria argentina. El consumo total de energía que cabría atribuir al transporte sería del orden del $50 \%$ de la energía final consumida, si es que consideramos la energía consumida por los vehículos desde "la cuna hasta la tumba"6 (Esteban y Sanz, 1996). Todo lo cual acentúa las emisiones de $\mathrm{CO} 2$, agravando el efecto invernadero. Además, la industria del transporte en general, y las del automóvil y del

\footnotetext{
6 Es decir, desde la extracción de materiales para la fabricación de los vehículos, durante la fabricación de los mismos, más el consumo durante su vida útil, así como durante el tratamiento y eliminación de los residuos generados cuando acaba su vida útil.
} 
transporte por carretera en particular, son de las más demandantes de recursos minerales de todo tipo. Esta demanda de minerales está provocando que el mundo se esté convirtiendo en una gran mina (Young, 1992), por el intenso desarrollo de la minería a cielo abierto para satisfacer esta sed insaciable de minerales, que hace posible el petróleo y que provoca un tremendo impacto ambiental. Igualmente, la creación de infraestructuras de transporte implica un elevado impacto paisajístico y trocea el territorio, provocando un paisaje roto, lo que repercute en una fuerte pérdida de biodiversidad.

Pero también los costes sociales de la movilidad motorizada están empezando a aflorar con fuerza. Por un lado, el desarrollo de la movilidad motorizada por carretera tiene los efectos de una Guerra de Baja Intensidad. El transporte por carretera se ha convertido en una especie de Moloch al que se sacrifican cientos de miles de vidas humanas en el mundo, así como millones de heridos como resultado de la "violencia vial". Esta "violencia vial" es especialmente importante en los países periféricos, pues el avejentamiento del parque móvil, la debilidad de la reglamentación por carretera y el uso de las vías por múltiples tipo de vehículos, incluidos los de tracción animal, los hace relativamente más vulnerables. En India hasta hay que ir sorteando en las autopistas las vacas (de carácter sagrado en ese país) que irrumpen en las mismas.

En esta Guerra de Baja Intensidad hay también muchas víctimas inocentes, como son los peatones y ciclistas. Esta guerra en gran medida oculta supone uno de los gastos más importantes en los sistemas de salud de todos los países, aparte de un inmenso drama humano (Estevan y Sanz, 1996, Estevan, 2008). Pero la tasa de mortalidad y de afecciones a la salud debida al transporte motorizado no se agota en los accidentes, sino que es resultado también de los elevados niveles de contaminación alcanzados en los espacios metropolitanos, especialmente en los periféricos donde los requerimientos en cuanto a la calidad de los carburantes y motores de los vehículos suelen ser menores. En ningún sector quizás como en el transporte por carretera se puede ver, si se quiere, el lado perverso de la técnica, pero éste ha permanecido oculto por los enormes intereses económicos que se mueven en torno al mismo, y por la avalancha de publicidad que lo promueve. De las 10 mayores empresas del mundo, 6 están relacionadas con el petróleo y tres son del sector del automóvil, y la primera es Wal Mart, cuya hegemonía global no se puede entender sin el transporte motorizado (ver cuadro 1).

Finalmente decir que una de las consecuencias del nuevo despliegue de la lengua de lava metropolitana en el mundo, y de la potenciación del transporte por carretera correspondiente, ha sido el incremento de los gastos de explotación del transporte colectivo y el deterioro en general de su calidad. El desarrollo urbano-metropolitano crecientemente disperso hace cada vez más difícil el mantener un transporte colectivo de amplia cobertura, barato y de calidad, debido a los costes que conlleva. Además, la cada día mayor privatización del transporte colectivo, sobre todo del ferrocarril convencional, redunda en la crisis del transporte como un servicio público de amplia cobertura. El transporte ferroviario interurbano convencional (no de alta velocidad) está cada vez más orientado hacia el transporte de mercancías, principalmente de contenedores, en los principales ejes de interrelación, siendo operado por grandes empresas privadas. 


\begin{tabular}{|l|l|}
\hline \multicolumn{2}{|l|}{ LAS DIEZ MAYORES EMPRESAS DEL MUNDO } \\
\hline 1 & 1 Wal Mart- EEUU (distribución comercial) \\
\hline 2 & 2 ExxonMobil Corporation - EEUU (petrolera) \\
\hline 3 & 3 Royal Dutch Shell - Angloholandesa (petrolera) \\
\hline 4 & 4 BP - Reino Unido (petrolera) \\
\hline 5 & 5 General Motors - EEUU (producción de automóviles) \\
\hline 6 & 6 Toyota Motor - Japón (producción de automóviles) \\
\hline 7 & 7 Chevron - EEUU (petrolera) \\
\hline 8 & 8 DaimlerChrysler - Alemania (producción de automóviles) \\
\hline 9 & 9 ConocoPhillips - EEUU (petrolera) \\
\hline 10 & 10 Total-Fina-Elf- Francia (petrolera) \\
\hline
\end{tabular}

Cuadro 1. Fuente: Fortune 500 (2007)

De hecho se están cerrando gran número de líneas en servicios interurbanos en la propia UE, uno de los espacios mejor dotados hasta ahora de ferrocarril convencional, al tiempo que se abren nuevas líneas de alta velocidad que sólo conectan las principales metrópolis, con unos costes de ejecución muy elevados, que consumen abundantes recursos públicos, que tienen unas tarifas prohibitivas para amplios sectores sociales y que dejan por el camino a muchas "ciudades perdedoras"; es decir, aquellos núcleos urbanos de menor tamaño que no quedan conectados. Cuanta más velocidad, pues, menor equidad social y territorial. Sería hora, por tanto, de empezar a desenmascarar todo lo que contiene la trastienda del sistema de transporte mundial que ha estado impulsando el capitalismo global en estos últimos treinta años.

\section{La Nueva Babel y la crisis social de la metrópoli postmoderna}

La metrópoli multicultural y su crisis social se empiezan ya a incubar al final del periodo anterior del crecimiento de la metrópoli, en la década de los 60 del siglo XX, sobre todo en EEUU. Un país crisol de flujos migratorios desde antes de su creación, una parte importante de ellos forzados: los esclavos provenientes de África. En este sentido, el estallido social en 1965 del barrio de Watts en Los Ángeles, un gueto negro, marca un verdadero hito en la irrupción de una nueva conflictividad social, y es un primer anuncio de la futura ingobernabilidad de las metrópolis. Un levantamiento popular de rabia de la población negra marginada, que acabó en incendios y saqueos de los supermercados de la zona, inauguraba por así decir el inicio de la crisis de la metrópoli contemporánea, apareciendo un tipo de conflictividad social muy distinta de la conflictividad obrera tradicional. El espacio del conflicto era el gueto metropolitano, no la fábrica. Este tipo de estallidos sociales, o riots, en terminología anglosajona, no saltaría a Europa hasta los 70 en Gran Bretaña, en los barrios más degradados de sus metrópolis multiétnicas y multiculturales, y más tarde en los 80 en otras metrópolis de Europa occidental, en barrios de similares características. Estos estallidos sociales, este auge de comportamientos desordenados, esta crisis de gobernabilidad de las metrópolis centrales eran indicadores de una creciente desintegración social de los principales espacios urbanos.

Pero las metrópolis centrales en este último periodo van a ganar en complejidad étnica y cultural, convirtiéndose en Nuevas Babeles, pues no en vano se han incrementado fuertemente los flujos migratorios desde los espacios periféricos en 
estos años ${ }^{7}$; pero también profundizan sus procesos de desestructuración y marginación social, y todo ello va a provocar erupciones sociales de especial intensidad. Entre ellas podríamos destacar las ocurridas otra vez en Los Ángeles, en 1992, tras la muerte de Rodney King a manos de la policía, que incendió muchas otras metrópolis estadounidenses durante días, haciendo necesaria la intervención del Ejército (Guardia Nacional) para sofocarla; o la rebelión de las banlieues parisinas de 2005, que hizo arder literalmente París, y a continuación la mayoría de los espacios urbanometropolitanos franceses, prolongándose los conflictos durante un mes, y que sólo se ahogaron también tras una durísima represión policial. Todo ello significó la explosión del odio y la humillación acumulados durante años en los guetos metropolitanos. Espacios donde se ceba la degradación urbana y la anomia, el paro, la precariedad extrema, la desestructuración familiar, la pobreza y los conflictos interétnicos. Es decir, la punta de un iceberg que a veces paradójicamente estalla como un volcán, incendiando coches, asaltando tiendas y hasta destrozando sus propios servicios públicos, un verdadero torbellino nihilista que bascula entre la rebelión antagonista desordenada y la guerra civil molar y molecular. Una guerra protagonizada en muchos casos por bandas juveniles de varones, con un fuerte componente étnico. $Y$ una guerra en la que casi siempre pierden los más débiles, y en especial las mujeres, niños y ancianos. Pero la base de ese iceberg es por supuesto mucho más amplia, pues se debe a la crisis de lo social en la metrópoli postmoderna, que permanece en gran medida invisible hasta que explota.

En las Ciudades Globales centrales dicha crisis

7 En la actualidad hay migrando más de 200 millones de personas en todo el planeta, esto es, el 3\% de la población mundial, y una gran parte de estas migraciones se orienta hacia los espacios centrales, aunque también otra parte importante se encamina hacia los semiperiféricos (Hdez Higueras, 2008). de lo social es resultado de distintos procesos. Creciente habitar en lo incierto y lo precario para una parte importante de su población, aquella que trabaja principalmente en los empleos terciarios de baja cualificación: empresas de limpieza, mantenimiento, recogida de basuras, etc. (complemento necesario del terciario decisional), en los que trabajan mujeres y jóvenes principalmente; al tiempo que se cronifica el desempleo al convertirse una parte considerable de la fuerza de trabajo en excedente, en torno a un $10 \%$ de la población, especialmente aquella de más edad (Roth, 2007). Progresiva crisis de identidad de la enorme diversidad de sus sujetos metropolitanos, y repliegue y hasta segregación espacial de acuerdo con las diferencias étnicas, nacionales o religiosas, aunque también se dan dinámicas de mestizaje. Nomadismo sin rumbo fijo de dichos sujetos por una ciudad estallada y fragmentada, que hace perder a la población urbana cualquier vínculo con el territorio circundante (desterritorialización y proliferación del nowhere-man o de la nowherewoman), lo que tiene verdaderas consecuencias antropológicas, y erosiona hasta el extremo la cohesión social. Progresiva dualización social entre los sectores más cosmopolitas y más interconectados globalmente (elites y la parte superior de las clases medias) y aquellos otros más ligados obligatoriamente a los territorios degradados de la metrópoli postmoderna, que desarrollan en ocasiones "nuevos tribalismos" en los barrios más marginados y más homogéneos étnicamente. Dualización asimismo por pirámides de edad, pues la población autóctona envejece cada vez más, mientras que la población inmigrante es fundamentalmente joven, y dualización igualmente en cuestiones de ciudadanía y de derechos entre esas dos poblaciones (creación del "Derecho de Extranjería", que choca frontalmente con la Declaración Universal de Derechos Humanos). Creciente habitar en hogares unipersonales o 
monoparentales (encabezados prioritariamente por mujeres), que alcanza muchas veces a más del $50 \%$ de su población, especialmente en los sectores de más renta y autóctonos, pues la población inmigrante es más gregaria (Beck, 2004). Crisis de los cuidados, al quebrar el modelo previo de convivencia y relación, que se agudiza aún más debido a la crisis de la familia nuclear y al estallido de la metrópoli sobre el territorio, así como por el hecho de la masiva incorporación de la mujer al trabajo asalariado en estos años; los cuidados sólo se garantizan para los sectores económicos más desahogados a través del mercado y del trabajo migrante (este es el polo positivo de la "cadena internacional de cuidados"), mientras el "Estado social" se bate en retirada en este campo y se incrementa la "doble jornada" para la mujer trabajadora. Auge de los "sin techo", especialmente intenso en EEUU, y profundización en la feminización de la pobreza. Y progresiva desaparición del espacio público de encuentro, interrelación y participación, como consecuencia de la segregación espacial y funcional y de la hegemonía del transporte motorizado y la velocidad.

La nueva metrópoli central se deshumaniza, se fragmenta, se atomiza, se gentrifica en sus espacios centrales, y se polariza, profundizando en su carácter de No-Ciudad. El estrés, el malestar social y la infelicidad colectiva se extienden imparables, y la sociedad urbana sobrevive a costa de una creciente medicalización, la única forma de sobrellevar el auge de la precariedad, incomunicación, soledad, inseguridad, ansiedad y depresión. Las "enfermedades" más extendidas en las metrópolis postmodernas. El espacio de "encuentro e interrelación" es ahora el de los Grandes Centros Comerciales, que explotan en este periodo y que ejercen su capacidad de atracción y fetichización por el cúmulo de mercancías que allí se ofrecen, impidiendo que la comunicación, el deseo y la fricción ciudadana circule libremente por las calles. Estos No-Lugares intentan recrear falsamente el bullicio de la vida urbana tradicional en sus espacios públicos.

Pero en ellos, el espacio público ha quedado totalmente desvirtuado, privatizado, mercantilizado, vigilado y acotado. En los últimos tiempos la vigilancia y el control se traslada cada vez más al conjunto de la nueva metrópoli, en especial a sus espacios centrales, donde todavía pervive el espacio público (calles y plazas), especialmente en Europa. Sin embargo, este espacio público está en proceso de fuerte degradación y mercantilización, pero en él todavía laten o se expresan las potenciales resistencias o dinámicas autónomas vitales que se quieren yugular. Es la hora de la "tolerancia cero" (nueva estrategia policial que surgió en Nueva York en los noventa), en teoría contra la criminalidad, pero su objetivo último es la represión y el control de lo social. Esta deriva se ha elevado a la enésima potencia tras el 11-S, no sólo en EEUU, sino en todos los espacios centrales, y en el mundo entero, y la "seguridad" se ha convertido en un importante campo de desarrollo tecnológico y empresarial, así como de acumulación de capital. En definitiva, se dispara el gasto de seguridad en la metrópoli, mientras que se descalabra el Estado social.

Por otro lado, en las Megaciudades Miseria de la Periferia la dualización y la crisis social alcanzan la máxima expresión, pues el colchón de las "clases medias" se reduce en muchos casos a su mínima expresión, mientras que proliferan los sectores marginales que viven absolutamente fuera de la economía formal, y por supuesto de la economía global. Además, la jibarización de las clases medias se ha agudizado en el último periodo debido a la imposición de las políticas neoliberales, sobre todo en América Latina y África, mientras éstas han crecido absolutamente pero quizás no tanto relativamente en China, India y el 
Sudeste asiático. El desempleo en las Megaciudades del Sur es alarmante oscilando entre el $25 \%$ al $50 \%$ de su población, y en muchas ocasiones superando ese "techo" (Roth, 2007; Davis, 2005). En estas conurbaciones se constata que el trabajo humano empieza a ser excedente de forma masiva, incapaz de ser absorbido por el empleo asalariado legal o alegal. Las Megaciudades Miseria de la Periferia se convierten pues en el Planeta de los Náufragos que nos describe Latouche (1994), ya que es en ellas donde se plasman espacialmente las consecuencias de un "Desarrollo" que produce más náufragos que navegantes. $Y$ son ellas, esos inmensos Hormigueros Humanos, las que han llevado a que la pobreza y la extrema pobreza tenga un rostro mundial cada vez más urbano-metropolitano, y no rural. Por otro lado, los sectores dirigentes se ven obligados a vivir en verdaderos guetos de riqueza, es decir, en espacios superprotegidos y cada día más militarizados, ante el temor al mar de pobreza circundante; aunque esta tendencia lleva ya también años desarrollándose en las metrópolis estadounidenses (Davis, 1992 y 2001), y de forma muy escasa aún en la Unión Europea.

La Megaciudad periférica también es una Nueva Babel, pero en general el grado de diversidad étnica y cultural de sus poblaciones es menor que en las metrópolis centrales, pues éstas se han convertido en verdaderos polos atractores del trabajo vivo joven a escala mundial, y en muchas ocasiones de la fuerza de trabajo periférica más cualificada, que cada vez más es preciso frenar levantando nuevos muros y sistemas de control. La Megaciudad periférica suele ser el polo atractor de los procesos de desarraigo del "Desarrollo" a escala local y regional. Además, la crisis social metropolitana en la Periferia se recrudece especialmente porque la Megaciudad Miseria suele reflejar el otro lado del espejo de la metrópoli central. Así, el abandono de una parte de las cohortes más jóvenes de su población hacia los espacios centrales (en parte para realizar labores de cuidado en el Centro), hace que los cuidados hacia sus mayores se resientan gravemente, o incluso hacia sus hijos que en muchos casos se abandonan en el camino, y que se dejan además en manos de los mayores. Este es el polo negativo de la cadena internacional de cuidados. Este proceso se agudizará en los próximos años conforme las poblaciones metropolitanas periféricas vayan envejeciendo. La crisis de los cuidados en las Megaciudades periféricas alcanzará una dimensión muy superior a la de las metrópolis centrales, si bien todavía perviven en ellas redes sociales de autoayuda más potentes que en los espacios centrales, incluso respecto a aquellos existentes en las poblaciones emigradas.

Por otro lado, el mercado formal de viviendas apenas cubre en general el $20 \%$ de la demanda, lo que puede ser un buen indicador del tamaño de sus "clases medias" (Davis, 2005). La mayoría de sus habitantes se construye sus propios chamizos o simplemente se instala en sus calles y aceras, e incluso en mitad de las autovías o en torno a los ferrocarriles que las cruzan, ocupando el poco terreno público existente, como en algunas de las Megaciudades indias y del sudeste asiático (Mumbai, Calcuta, Manila, etc.). Esos tejidos urbanos hiperdegradados son el ecosistema ideal para la proliferación de mafias locales de todo tipo, en conexión con redes de criminalidad organizada, con fuerte presencia de jóvenes varones (las Maras centroamericanas son un buen ejemplo de ello), y en ellos el Estado es incapaz de imponer su orden y su ley. Aparte de que muchas veces estas mafias y redes se interrelacionan con los cuerpos policiales corruptos. Esta inseguridad extrema se ensaña más con los más débiles: mujeres, niños y ancianos, sobre todo al caer la noche cuando la "calle" y el "barrio" pasan a ser coto exclusivo de los más agresivos y poderosos. 
La población que habita en las Megaciudades periféricas se ve obligada a aceptar esta nueva "ley de la selva" metropolitana, incapaz de poder sustraerse a estas dinámicas que la superan y de poder huir fuera de estas grandes conurbaciones hacia no se sabe dónde. Es como Cortés, se han quemado las naves y no es posible una vuelta al campo, que por otro lado es ya propiedad de la oligarquía agraria o del agrobusiness. Una de las enfermedades más extendidas en estos espacios metropolitanos es asimismo la depresión, pero también la desesperación y la locura, únicas formas de reaccionar a un entorno y a una situación extrema que te supera.

En algunas Megaciudades Miseria brasileñas; Sao Paulo y Río de Janeiro, principalmente, los problemas de orden público e inseguridad se han convertido ya en un verdadero problema de Estado. El Estado es incapaz de controlar los territorios de estas metrópolis, sobre todo gran parte de sus favelas (los barrios más degradados), y garantizar su gobernabilidad. Las mafias y redes criminales han lanzado verdaderos desafíos al Estado, llegando en ocasiones a paralizar dichas Megaciudades, y desde Brasilia el poder central se ha visto obligado a enviar el Ejército para garantizar el orden. Como Mike Davis (2005) nos alerta, citando un informe elaborado por el propio Pentágono estadounidense, estas áreas superdegradas de las Megaciudades serán el principal campo de batalla del siglo XXI, y EEUU está rediseñando parte de su estrategia militar para poder hacer frente a una guerra de baja intensidad y duración ilimitada contra los pobres urbanos del mundo. Pero ello será así allí donde le convenga hacerlo, debido a los intereses económicos en juego, en otros seguramente se dejara que las Megaciudades se consuman en sus propias contradicciones internas. El nuevo capitalismo global, en su loca huida hacia adelante, hace tiempo que ha dejado de estar interesado en garantizar la reproducción social sobre el territorio, sobre todo en las Megaciudades periféricas donde es cada vez más incapaz de hacer viable su gobernabilidad.

Madrid, octubre, 2008

PD: El inicio del fin de la era de los combustibles fósiles en el que todo indica que estamos a punto de entrar, debido a la llegada del llamado pico del petróleo, pondrá fin a la expansión urbana a escala mundial, que ha sido especialmente intensa a lo largo de todo el siglo XX, y en especial en los últimos 30 años. El declive energético planetario impactará con especial fuerza en las metrópolis y sobre el transporte motorizado y la agricultura industrializada. Todo ello se verá agravado por las crisis globales en marcha, de carácter financiero, económico, alimentario, climático y ecológico, con fuertes interrelaciones asimismo con la crisis energética mundial, a la que se suma la crisis de hegemonía de EEUU. Los efectos de todas estas crisis se manifestarán también con especial intensidad en las metrópolis, que pasarán de ser los puntos fuertes del territorio a convertirse en sus enclaves más frágiles e ingobernables. En definitiva, nos enfrentamos a una verdadera crisis civilizatoria de enormes dimensiones. Es por ello por lo que muy seguramente veremos a medio y largo plazo una regresión hacia un mundo menos urbanizado, menos industrializado y menos globalizado, así como más ruralizado y más "localizado", con una brusca contracción de la movilidad motorizada mundial (Fdez Durán, 2008). Sobre estas cuestiones se profundizará en el libro más amplio en proceso de elaboración, enmarcándolas en una amplia reflexión histórica de long durée. 


\section{Referencias}

ARRIGHI, Giovanni: “Adam Smith en Pekín”. Akal (Cuestiones de Antagonismo). Madrid, 2007.

AUGÉ, Marc: "Los No Lugares. Espacios del Anonimato. Una Antropología de la Sobremodernidad”. Gedisa. Madrid, 1993.

BARREDA, Andrés: "Geopolítica, Recursos Estratégicos y Multinacionales". Jornadas: Las Multinacionales Españolas en América Latina”. Paz con Dignidad y Hegoa, Bilbao, 2005.

BARREDA, Andrés et al: "Atlas Mundial del Petróleo". Oilwatch-UICN. 2007.

BARREDA, Andrés: "EEUU es Adicto al Petróleo". En Biodiversidad, n 54, octubre, 2007.

BARREDA, Andrés: "Geostrategies of European TNC"s in Latin American Countries". Rolling Back the Power of TNC"s (Enlazando Alternativas-TNI). Roma, febrero, 2008.

BEAUCHARD, Jean: “Ou Va la Ville?". En Actions et Recherches Sociales, $n^{\circ}$ 1. París. Enero, 1993.

BECK, Ulrick: "La Ciudad del Riesgo. Arquitectura en la Modernidad, Reflexiones". En Archipiélago, $n^{\circ} 62.2004$.

CHOAY, Françoise: "La Nueva Babel. El Reino de lo Urbano y la Muerte de la Ciudad". En Arquitectura Viva, n³5, marzo-abril 1994.

CHRISTIAN, David: "Mapas del Tiempo. Introducción a la Gran Historia”. Ed. Crítica. Barcelona, 2005.

DAVIS, Mike: "City of Quartz: Excavating the Future of Los Angeles". Vintage Books, New York, 1992.

DAVIS, Mike: "Control Urbano: La Ecología del Miedo". Virus. Barcelona, 2001.

DAVIS, Mike: "Planeta de Ciudades-Miseria". En Monthly Review. www.newleft.net. 2005. Traducción al castellano en editorial Foca. Madrid, 2007.

ENDE, Michael: “Momo”. Alfaguara. Madrid, 1994. ESTEVAN, Antonio y SANZ, Alfonso: "Hacia la
Reconversión del Transporte en España". La Catarata. Madrid, 1996.

ESTEVAN, Antonio: "Último Acto: El Coche Devora el Planeta”. En El Ecologista $n^{\circ}$ 56. 2008.

FERNÁNDEZ DURÁN, Ramón: "El Futuro de las Comunicaciones: Transporte versus Sostenibilidad”. En Garcia Barreno (director): "La Ciencia en tus Manos”. Espasa. Madrid, 2000.

FERNÁNDEZ DURÁN, Ramón: “Destrucción Global versus Regeneración Local".

En LOPEZ, Daniel y López, Ángel: "Con la Comida no se Juega”. Traficantes de Sueños. Madrid, 2004.

FERNÁNDEZ DURÁN, Ramón: "El Tsunami Urbanizador Español y Mundial”. Virus. Barcelona, 2006.

GOTTMAN, Jean: "Megalópolis, or the Urbanization of the Northeastern". En Economic Geography, julio, 1957.

HARVEY, David: "Breve Historia del Neoliberalismo". AKAL (Cuestiones de Antagonismo). Madrid, 2007.

HEINBERG, Richard: "Se Acabó la Fiesta. Guerra y Colapso Económico en el Umbral del Fin de la Era del Petróleo". Barrabes Editorial. Benasque (Huesca), 2006.

HERNÁNDEZ VIGUERAS, Juan: "La Desregulación de los Mercados Financieros como Causa de la Pobreza". Jornadas "El Derecho a No Emigrar". Consejo General del Poder Judicial. Madrid, mayo, 2008.

HERNÁNDEZ VIGUERAS. Juan: "La Europa Opaca de las Finanzas". Icaria. Barcelona, 2008.

IBARRONDO, Juan: "Retazos en la Red". Bassarai (Narrativa). Vitoria-Gasteiz

ILLICH, Iván: “Energia y Equidad”. Barral editores. Barcelona, 1974.

KEROUAC, Jack: "On the Road". Viking Press. New York, 1957, 2005.

KOTKIN, Joel: "La Ciudad: Una Historia global”. 
Debate. Barcelona, 2006.

LATOUCHE, Serge: "El Planeta de los Náufragos. Ensayo sobre el Postdesarrollo". Acento Editorial. Madrid, 1994.

LEE, Kai: "Un mundo en Proceso de Urbanización". El Estado del Mundo 2007. Icaria-WWI. Barcelona, 2007.

LOS AMIGOS DE LUDD: "Las llusiones Renovables. La Cuestión de la Energía y la Dominación Social". Muturreko Burutazioak. Bilbo, 2007.

MAGNAGHI, Alberto: "Le Project Local". Mardaga. París, 2003.

MUMFORD, Lewis: "The City in History. Its Origins. Its Transformations, and Its Prospects". Harbinger Book. New York, 1961.

MUMFORD, Lewis: "The Highway and the City". Harcourt Brace. New York, 1963.

NAREDO, José Manuel: "Ciudades y Crisis de Civilización". En Documentación Social n 119, abril-junio, 2000 www.habitat.aq.upm.es

ROTH, Kart Heinz: "El Estado del Mundo. Contraperspectivas". Traficantes de Sueños. Madrid, 2007.

SANZ, Alfonso: "Autópolis, Telépolis, Gilípolis". Jornadas "Mujer en Telépolis". Inédito. Madrid, 1997.

SASSEN, Saskia: "The Global City: New York, London, Tokio". Princeton University Press. Princeton, 1991.

SASSEN, Saskia: "La Ciudad, Espacio Esencial para Afrontar el Desafío Ecológico". Segundas Jornadas sobre Sostenibilidad. IAU+S. Escuela Arquitectura de Madrid, febrero-marzo, 2006.

SIMMEL, Georg: "The Philosophy of Money". Routledge. New York, 1990.

SWEDETRACK: "Motor Vehicle Explosion". www.swedetrack.com 2008.

VARELA, José Antonio: "El Coche ese Centauro Moderno con Culo de Escape" www.eutsi.org 2008.

VEGA, Pilar: “¿Cómplices o víctimas? Las muje- res y el deterioro ecológico provocado por el actual modelo territorial". En Revista Ecologista, $n^{\circ}$ 39, primavera, 2004.

VEGA, Pilar: "Tiempo, Territorio y Transporte". En "Gestión del Tiempo y Evolución de los Usos del Tiempo" (AAVV). Vision Net. Madrid, 2007.

VERDAGUER, Carlos: "El Paisaje Análogo. Un Sueño de la Modernidad". En Revista de Occidente n $^{\circ} 204$, abril, 1998.

WONG, Susanne: "Running on Empty. China Gambles on Massive Water Transfers to Solve Crisis". World Rivers Review. Vol. 22. number 4. December 2007.

WWR: "No Future without Addressing the Past". World Rivers Review. Vol. 22. number 4. December 2007.

YOUNG, J.E.: "La Tierra Convertida en una Gran Mina”. En Brown, Lester (ed.): "La Situación del Mundo en 1992". WWI-Apóstrofe. Barcelona, 1992.

\section{Cita del artículo}

FERNANDEZ DURAN, R. Un planeta de metrópolis (en crisis). Hábitat y Sociedad, 2011, n² 2, p. 205-239<www.habitatysociedad.us.es $>$.

Editado originalmente como:

FERNANDEZ DURAN, R. Un planeta de metrópolis (en crisis). Zambra, Baladre, CGT y Ecologistas en Acción, 2010.

http://dx.doi.org/10.12795/HabitatySociedad.2011.i2.12 